\title{
Chapter 15 \\ Large-Scale Thermo-chemical Structure of the Deep Mantle: Observations and Models
}

\author{
Frédéric Deschamps, Yang Li and P.J. Tackley
}

\begin{abstract}
Seismic tomography indicates that the lowermost mantle, from $2400 \mathrm{~km}$ down to the core-mantle boundary (CMB) is strongly heterogeneous at large wavelengths. The most striking features are two large low-shear-wave velocity provinces (LLSVPs), where shear-wave velocity drops by a few percent compared to averaged mantle. Several seismic observations further show that lowermost mantle seismic anomalies cannot be purely thermal in origin. Compositional anomalies are required to fully explain observations like the anti-correlation between shear- and bulk-sound velocities, and the distribution of density mapped by normal modes. In the meantime, models of thermo-chemical convection indicate that reservoirs of dense, chemically differentiated material can be maintained in the lowermost mantle over long periods of time and that thermal plumes rising up to the surface are generated at the surface of these reservoirs. Model parameter searches indicate that maintaining such reservoirs requires a moderate density contrast between dense and regular material and a large thermal viscosity contrast. Current models of thermo-chemical convection also explain details revealed by travel time and seismic waveform data, in particular the LLSVP sharp edges, and the distribution of plumes at the surface of LLSVPs. A remaining question is the detailed nature of the lower mantle large-scale chemical heterogeneities. Reservoirs of dense material may result either from early partial differentiation of the mantle or recycling of oceanic crust (MORB). Seismic sensitivities inferred from a coherent mineral physics database suggest that LLSVPs are better explained by warm material enriched in iron and silicate, than by highpressure MORB. By contrast, if colder than the surrounding mantle by $\sim 400 \mathrm{~K}$,
\end{abstract}

\footnotetext{
F. Deschamps $(\square)$

Institute of Earth Sciences, Academia Sinica, 128 Academia Road Sec. 2,

Nangang, Taipei 11529, Taiwan

e-mail: frederic@earth.sinica.edu.tw
}

Y. Li · P.J. Tackley

Institute of Geophysics, Swiss Federal Institute of Technology Zurich,

Sonnegstrasse 5, 8092 Zurich, Switzerland 
high-pressure MORB explains well seismic velocity anomalies in regions where ancient slabs are expected to rest, e.g., beneath the Japan subduction zones and beneath Central and South America. The post-pervoskite phase certainly plays a significant role in explaining seismic observations, in particular the $\mathrm{D}^{\prime \prime}$ discontinuity, but is unlikely to explain all seismic observations alone.

Keywords Mantle structure - Mantle composition - Mantle dynamics - LLSVPs • Thermo-chemical convection

\subsection{Introduction}

Our description of the Earth's deep mantle structure and dynamics has changed considerably during the past decade, aided by advances in seismology, high-pressure mineral physics, and geodynamics. The deep mantle appears much more heterogeneous than previously expected, both at small-scale (i.e., up to a few tens of kilometers; see Rost et al., this volume) and large-scale (typically $1000 \mathrm{~km}$ across and more). From depths of about $2400 \mathrm{~km}$ down to the core-mantle boundary (CMB), seismic observations such as the radial and lateral variations in seismic ratios $d \ln V_{\mathrm{P}} / \mathrm{d} \ln V_{\mathrm{S}}$ and $\mathrm{d} \ln V_{\Phi} / \mathrm{d} \ln V_{\mathrm{S}}$ (van der Hilst and Kárason 1999; Deschamps and Trampert 2003), distribution histograms of the shear-wave velocity anomalies (Deschamps and Trampert 2003; Hernlund and Houser 2008; Burke et al. 2008), and the anti-correlation between shear-wave and bulk-sound phase velocity (Ishii and Tromp 1999; Masters et al. 2000; Trampert et al. 2004; Houser et al. 2008), are better explained if chemical heterogeneities are present in the deep mantle although a thermally dominated structure have also been advocated (see Davies et al., this volume). Seismic observations invalidate the hypothesis that low-shear-wave velocity provinces (LLSVPs) observed beneath Africa and beneath the Pacific result from purely thermal anomalies. Normal-mode tomography (Ishii and Tromp 1999; Trampert et al. 2004; Mosca et al. 2012) gives further constraints on the deep mantle density distribution, which further support the presence of large-scale compositional anomalies.

Due to the presence of compositional heterogeneities in the deep mantle, modeling mantle dynamics requires the use of thermo-chemical convection simulations. Compositional heterogeneities, in addition to temperature variations, cause lateral variations in density, which in turn influence the flow pattern and the heat and mass transfers. The key parameter controlling the thermo-chemical structure of the system is the density contrast between the chemical anomalies and the regular material. When an initial dense layer is present at the bottom of the system, the density contrast between the dense and regular materials controls the stability and shape of this layer (e.g., Davaille 1999; Tackley 2002; McNamara and Zhong 2004; Deschamps and Tackley 2009). Models in which reservoirs of dense material result from the segregation of recycled oceanic (e.g., Gurnis 1986; Christensen 1989; Olson and Kincaid 1991; Christensen and Hofmann 1994) also indicate that the size and stability of these reservoirs strongly vary with the density contrast between the recycled and regular materials. 
Mantle petrology is based on 5 main oxides $\left(\mathrm{CaO}, \mathrm{FeO}, \mathrm{MgO}, \mathrm{Al}_{2} \mathrm{O}_{3}\right.$, and $\mathrm{SiO}_{2}$ ) from which the most abundant mantle minerals are built. In addition, MORB requires $\mathrm{Na}_{2} \mathrm{O}$ in weight fraction up to $2.0 \%$. The detailed petrology further depends on the stability of each mineral, therefore on temperature and pressure. Chemical heterogeneities in the deep mantle may thus consist of variations in the fractions of these 5 oxides compared to a reference composition, e.g., the average pyrolitic composition (Ringwood 1975). The exact mechanism responsible for generating these variations is, however, still unknown. A straightforward source of heterogeneities is the recycling of subducted slabs in the deep mantle, as suggested by tomographic images (e.g., van der Hilst et al. 1997). Compared to the hypothetical pyrolite, MORB is strongly depleted in $\mathrm{MgO}$ and enriched in $\mathrm{SiO}_{2}, \mathrm{CaO}$, and $\mathrm{Al}_{2} \mathrm{O}_{3}$, and to a lesser extent FeO (e.g., Ricard et al. 2005). Another possible source of chemical heterogeneity is the survival of reservoirs resulting from the early partial differentiation of the mantle. Possible mechanisms of differentiation include the crystallization of regular (i.e., crystallizing upwards from the $\mathrm{CMB}$ ) or basal magma oceans (Solomatov and Stevenson 1993; Labrosse et al. 2007; Solomatov 2007), upside-down differentiation (Lee et al. 2010), and the recycling of an early crust (Boyet and Carlson 2006; Tolstikhin et al. 2006). Alternatively, if the Earth was built from enstatite chondrites, an enrichment of the lower mantle in iron and silicates may result from the a two-stage scenario of core formation, including a giant impact, and would thus not require early differentiation of the mantle (Kaminski and Javoy, this volume).

In addition to thermal and chemical anomalies, the phase change from $\mathrm{MgSiO}_{3}$ perovskite to post-perovskite (Murakami et al. 2004; Oganov and Ono 2004) may be needed to fully explain available seismic observations. The transition from perovskite to post-perovskite may correspond to the $\mathrm{D}^{\prime \prime}$ discontinuity, which is locally observed in the lowermost mantle (Wookey et al. 2005). It was furthermore suggested that lateral variations in the depth of the transition from perovskite to post-perovskite is responsible for the anti-correlation between shear-wave and bulk-sound velocity (Wookey et al. 2005; Hirose 2007; Hutko et al. 2008). Davies et al. (2012) proposed that seismic tomography can be fully explained by distributions of post-perovskite induced by lateral variations of temperature, but other studies (Deschamps et al. 2012; Mosca et al. 2012) arrived at the opposite conclusion.

In this chapter, we briefly review seismic observations that support the presence of large-scale chemical heterogeneities in the deep Earth mantle. We then discuss the parameters of convection models that allow reservoirs of dense material to be maintained in the deep mantle for a long period of time, and illustrate this with new models of thermo-chemical convection in spherical geometry. We finally discuss the possible nature of chemical heterogeneities and the role of the post-perovskite phase transition.

\subsection{Thermo-chemical Structure: Seismological Hints}

Seismic data are, so far, the most detailed information available to infer the Earth's mantle structure. Global seismic tomographic images have now reached a consensus concerning the large-scale (i.e., $\sim 1000 \mathrm{~km}$ across, or more) structures (for comparison 
between recent models, see Schaeffer and Lebedev 2013; Ritsema et al. 2011). The strongest lateral heterogeneities are found at the top (shallower than $400 \mathrm{~km}$ ) and at the bottom (deeper than about $2400 \mathrm{~km}$ ) of the mantle. In between these depths, no notable large-scale structure is observed, and the RMS seismic velocity variation is small, $0.5 \%$ or less. Below the surface, anomalies of shear-wave velocity are well correlated with surface tectonics down to depths of about 200-300 km (Schaeffer and Lebedev, this volume). The ocean-continent distribution clearly appears, with the slowest velocity being observed under mid-oceanic ridges. Within continents, tectonically active regions also appear slower than average, whereas high-velocity roots are observed beneath cratonic areas. In the lowermost mantle, the seismic tomographic images are dominated by two large low-shear-wave velocity provinces (LLSVPs) located along the equator beneath Africa and the Pacific. These regions were first observed by global tomographic models in the 1990s (Tanimoto 1990; Su et al. 1994; Li and Romanowicz 1996), and more recent models provided refined images of these structures (e.g., Antolik et al. 2003; Houser et al. 2008; Kustowski et al. 2008; Ritsema et al. 2011). Tomographic models of the mantle beneath Africa (Ritsema et al. 1999) show that the African LLSVP has globally the structure of a ridge with a NW/SE direction and is locally tilted toward the east. In contrast, the Pacific LLSVP appears roughly oval in shape (e.g., Houser et al. 2008; Ritsema et al. 2011). Importantly, LLSVPs are also observed by normal-mode tomography (Ishii and Tromp 1999; Trampert et al. 2004; Mosca et al. 2012). A cluster analysis applied to recent tomographic models indicates that LLSVPs are robust structures, not artifacts (Lekic et al. 2012). An important methodological refinement of the past decade is probabilistic tomography, first introduced by Resovsky and Trampert (2003), which allows the determination of full probability density functions (pdf) (rather than single values) of seismic velocity and density anomalies at each point of the model. This provides robust estimates of the error bars in the tomographic images. Global models of probabilistic tomography published so far (Trampert et al. 2004; Mosca et al. 2012) are based on normal-mode data. A limitation of these models is that they are restricted to spherical harmonic degrees 2, 4, and 6. Nevertheless, they indicate that LLSVPs are robust structures.

Details on the lower mantle seismic structure, in particular the shape and extent of LLSVPs, may be obtained from waveform modeling and travel times of seismic phases sampling the lowermost mantle, including $S, S_{\text {diff, and phases reflected at }}$ the top of the outer core $(\mathrm{ScS})$ or traveling through it (SKS). Keeping in mind that their interpretations involve trade-off between the amplitude, shape, and size of the velocity anomaly, these observations reveal interesting local features. The complexity of SKS waveforms and the differential travel times (relative to $S$ waves) of $\mathrm{ScS}$ and SKS phases sampling the lowermost mantle beneath southern Africa are well explained by an eastward tilt of the African LLSVP (Ni et al. 2002; Ni and Helmberger 2003). Travel time delays further suggest that in this region, the African LLSVP has sharp boundaries, typically around $50 \mathrm{~km}$ (Ni et al. 2002). Around equatorial latitudes, $\mathrm{S}$ and $\mathrm{P}$ travel time and waveform data indicate that the African LLSVP has a bell shape with a wide ( 4000 km west to east) base (Wang and Wen 2007). Additional constraints are also available for the Pacific 
LLSVP. S travel times and waveforms (He and Wen 2009) and tomographic models (Ritsema et al. 2011) suggest that it may split into a western and an eastern province with a gap of several hundreds of kilometers in between. Both provinces have a trapezoidal shape, but the western region has stronger topography than the eastern region. Sharp boundaries at the southern edge of the Pacific LLSVP have been reported from the analysis of $\mathrm{SH}_{\text {diff }}$ waveforms (To et al. 2005), as well as at its western edge (Takeushi et al. 2008).

First hints for the presence of chemical heterogeneities in the deep mantle are provided by seismic ratios. The sharp increase of the laterally averaged ratio between compressional and shear-wave velocity anomalies $\left(\mathrm{d} \ln V_{\mathrm{S}} / \mathrm{d} \ln V_{\mathrm{P}}\right)$ in the deep mantle (van der Hilst and Kárason 1999; Masters et al. 2000) and the strong lateral dispersion of this ratio at a given depth (Deschamps and Trampert 2003; Deschamps et al. 2007) are more easily explained if the seismic velocity anomalies are not purely thermal in origin. Furthermore, the distribution histograms of shear-wave velocities anomalies in the lowermost mantle have a double peak (Deschamps and Trampert 2003; Hernlund and Houser 2008; Burke et al. 2008), which again is better explained if chemical heterogeneities are present. A key observation from seismic tomography is the anti-correlation between shear-wave velocity $\left(V_{\mathrm{S}}\right)$ and bulk-sound velocity $\left(V_{\Phi}\right)$ anomalies in a layer extending from about $2400 \mathrm{~km}$ down to the CMB (Su and Dziewonski 1997; Masters et al. 2000; Houser et al. 2008). In particular, $V_{\Phi}$ is faster than average (by up to about $1 \%$ ) throughout the region spanned by LLSVPs. Because the temperature derivatives of $V_{\mathrm{S}}$ and $V_{\Phi}$ are both negative throughout the Earth's mantle (e.g., Trampert et al. 2001; Deschamps and Trampert 2003), purely thermal anomalies are unable to explain an anti-correlation between $V_{S}$ and $V_{\Phi}$ anomalies, thus implying the presence of large-scale lateral variations in composition. It has recently been suggested that the anti-correlation between $V_{\mathrm{S}}$ and $V_{\Phi}$ anomalies may result from wavepropagation effects (Schuberth et al. 2011). However, the fact that normal-mode tomography, which is not affected by potential propagation effects of the body waves, also observes this anti-correlation (Ishii and Tromp 1999; Trampert et al. 2004; Mosca et al. 2012) strongly supports the hypothesis that it results from real structures. An additional observation pointing to the presence of compositional anomalies in the lowermost mantle is the de-correlation between seismic velocity anomalies and density anomalies mapped by normal-mode tomography (Ishii and Tromp 1999; Trampert et al. 2004; Mosca et al. 2012).

Seismic velocity anomalies result from variations in temperature and composition that one would like to map. A difficulty in solving this inverse problem is the trade-off that exists between temperature and composition. Sensitivities of shearwave and bulk-sound velocities to one particular parameter are different in amplitude, but usually have the same sign (e.g., Trampert et al. 2001; Deschamps and Trampert 2003). For instance, both shear-wave and bulk-sound velocities decrease with increasing amount of iron. A notable exception is $\mathrm{SiO}_{2}$, either free or in the form of perovskite, for which the sensitivity of $V_{\mathrm{S}}$ goes to zero in the deep mantle, whereas the sensitivity of $V_{\Phi}$ remains strongly positive (Deschamps et al. 2012). As a result, seismic velocities alone may qualitatively reveal the presence of 
thermal and chemical sources, but cannot quantitatively resolve the distributions in temperature and composition. A detailed mapping of thermo-chemical anomalies requires additional, independent observations, such as density distributions, which can be retrieved from normal-mode data (Ishii and Tromp 1999; Trampert et al. 2004; Mosca et al. 2012). Assuming that the chemically anomalous component consists of material enriched in iron and perovskite, and using appropriate equation of state modeling, Trampert et al. (2004) calculated distributions of temperature, iron, and perovskite in the lower mantle. Their calculations indicate that bulk-sound velocity and density anomalies are good proxies for the fraction of perovskite and the fraction of iron, respectively (Fig. 15.1). In contrast, shear-wave

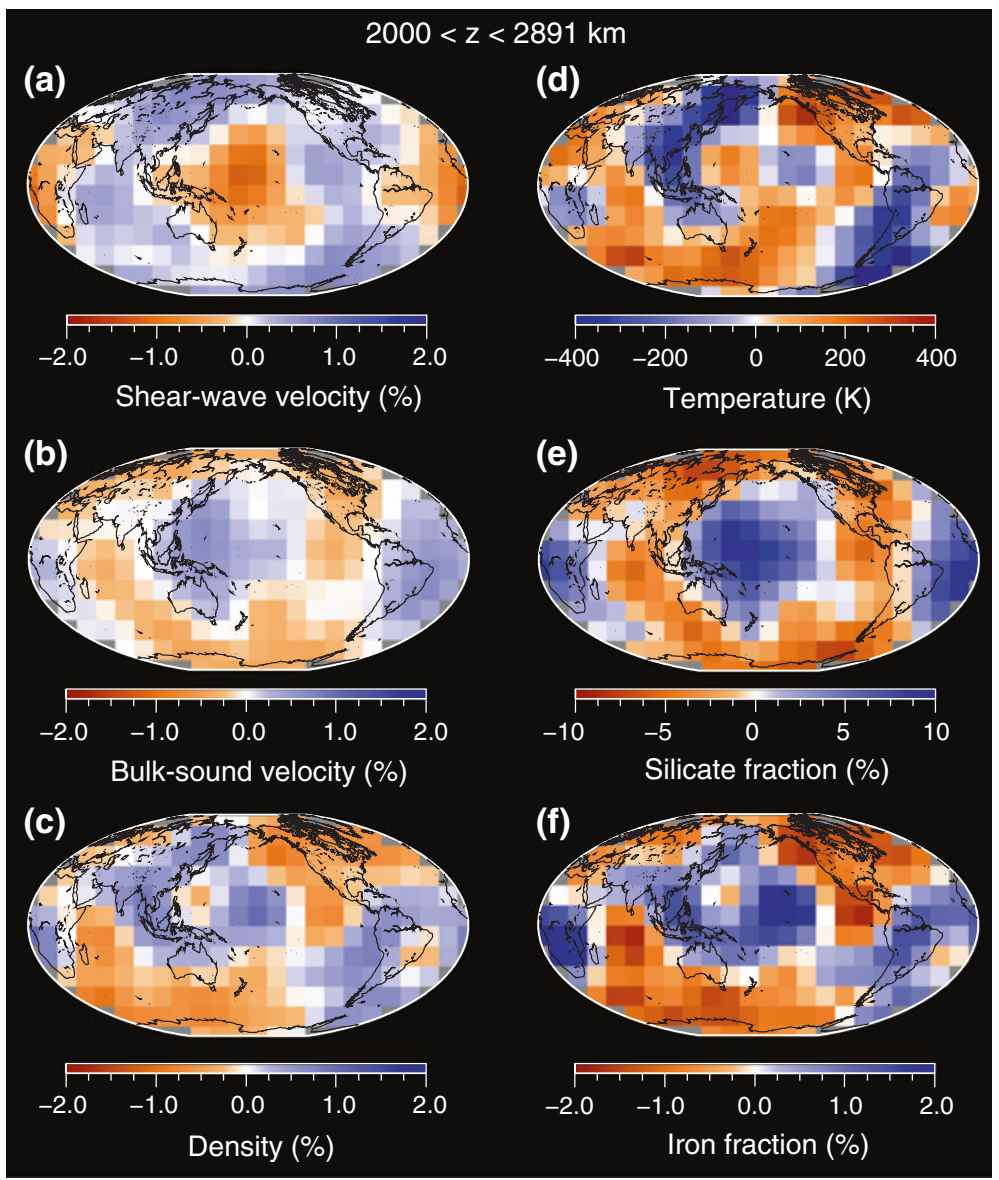

Fig. 15.1 Seismic (left column) and thermo-chemical (right column) structures from probabilistic tomography (Trampert et al. 2004) in the depth range 2000-2891 km. The seismic structure includes relative anomalies in a shear-wave velocity, $\mathbf{b}$ bulk-sound velocity anomalies, and $\mathbf{c}$ density anomalies. The thermo-chemical structure includes absolute anomalies in $\mathbf{d}$ temperature, $\mathbf{e}$ fraction of perovskite, and $\mathbf{f}$ fraction of iron 
velocity anomalies are not a good proxy for temperature anomalies, but likely result from lateral variations in both temperature and iron. Updated models of probabilistic tomography with a higher vertical resolution and accounting for the presence of post-perovskite (Mosca et al. 2012) have confirmed these results.

Another difficulty in interpreting tomographic models is that they may be biased by uneven data coverage and a priori information (mainly damping and smoothing) imposed by inversion methods. These effects should be accounted for when comparing seismic velocity distributions deduced from models of mantle dynamics, and those from tomographic models. The simplest filter is to add random Gaussian noise based on estimated uncertainties in seismic velocity anomalies (Deschamps et al. 2012). This approach is well suited for comparison with tomographic models based on Monte Carlo methods (such as probabilistic tomography), but may also be used for comparison with other models. For a more detailed comparison with a specific tomographic model, a filter may be designed from the resolution matrix of this model (e.g., Ritsema et al. 2007; Schuberth et al. 2009). Applying such filter to the seismic velocity distribution issued from purely thermal models of convection (which are dominated by short wavelengths structures) adds substantial smearing that smooth out the input distribution (Ritsema et al. 2007; Schuberth et al. 2009). Still, this smoothed distribution hardly explains the observed tomographic model. By contrast, the synthetic seismic velocity obtained from models of thermo-chemical convection provides a better match to seismic tomography (Ritsema et al. 2007).

In addition to thermal and chemical anomalies, other effects, including the presence of fluids or partial melts and lateral variations in the depth of phase transitions, can affect seismic observations. The phase transition from perovskite to post-perovskite is of particular interest for the lowermost mantle structure (for a detailed discussion on the seismic detection and presence of post-perovskite in the deep mantle, we refer to Cobden et al., this volume). The lateral variations in the depth at which the post-perovskite phase transition occurs may play a significant role in explaining several seismic features, including the $\mathrm{D}^{\prime \prime}$ discontinuity (Wookey et al. 2005) and arrival of diffracted seismic waves (Cobden et al. 2012; Cobden et al., this volume). However, both seismic sensitivities from mineral physics properties (Deschamps et al. 2012) and the most recent models of probabilistic tomography (Mosca et al. 2012) indicate that the details of seismic tomography cannot be explained only with thermal anomalies and lateral variations in the post-perovskite phase transition. We further discuss this point in Sect. 15.5.

\subsection{Models of Thermo-chemical Convection}

Seismic tomography indicates that large-scale compositional heterogeneities are likely present in the deep mantle, with LLSVPs being chemically distinct from the rest of the mantle. Other geophysical constraints (Torsvik et al. 2008; Dziewonski et al. 2010; Conrad et al. 2013; Sect. 15.6) further indicate that LLSVPs have remained stable 
during the past $300 \mathrm{Myr}$, and potentially over much longer periods of time. Models of convection describing mantle dynamics should therefore include compositional variations in addition to the thermal variations usually considered and be able to maintain large-scale thermo-chemical reservoirs during long periods of time.

A variety of experimental (e.g., Olson and Kincaid 1991; Davaille 1999; Jellinek and Manga 2002) and numerical (e.g., Hansen and Yuen 1988; Christensen and Hofmann 1994; Tackley 1998, 2002; McNamara and Zhong 2004, 2005; Tan and Gurnis 2005, 2007; Deschamps and Tackley 2008, 2009) models of thermo-chemical convection have been developed, showing strong stratification or a more complex structure, depending on the fluid properties. A major improvement was to perform calculations that account for compressible fluids, using either the anelastic (Tackley 1998), or the extended Boussinesq (Schott and Yuen 2004) approximation. In these approximations, viscous dissipation and adiabatic heating are present, and thermo-chemical properties are allowed to vary with depth through the prescription of a reference model. The decrease of thermal expansion with depth, which is well documented from mineral physics data (e.g., Anderson 1995), is particularly important because it weakens the thermal buoyancy in the deep mantle. As a result, chemical stratification or the development of stable thermo-chemical structures requires a smaller buoyancy ratio than in the classical Boussinesq approximation.

\subsubsection{Stability of Thermo-chemical Reservoirs: Important Parameters}

The mode of convection of a chemically heterogeneous fluid, and therefore the fluid thermo-chemical structure, is controlled by several parameters, including the buoyancy ratio (measuring the chemical density contrast relative to the top-to-bottom thermal density contrast), the fraction of dense material, and the rheology of the fluid. Among these parameters, the buoyancy ratio, $B$, has a particular importance because it controls the stratification of the system and the amplitude of the deformation of the dense layer (e.g., Davaille 1999; Le Bars and Davaille 2004; McNamara and Zhong 2004; Jaupart et al. 2007). Variations in $B$ lead to different patterns, from a stable layer (large $B$ ), to a fully unstable layer (small $B$ ). The analogue experiments of Davaille (1999) observe two regimes of convection, depending on the density contrast between the dense layer and the overlying material. If the density contrast is smaller than $1 \%$, domes of dense material oscillate vertically, but dense and regular material remain unmixed. For larger contrasts, the system is stratified, i.e., the layer of dense material remains stable. Strong stratification is also observed by numerical models, in cases for which the buoyancy ratio is too large. A strong stratification is, however, not desirable in the case of the Earth's mantle, because it is not observed by seismic data and models. Moderate buoyancy ratios lead to large thermo-chemical piles, whose spectral content agrees well with that of thermo-chemical heterogeneities observed by probabilistic tomography 
(Deschamps et al. 2007). Unfortunately, these structures are short-lived, and they do not survive convection (Deschamps and Tackley 2008). Dense and regular materials quickly mix, and the amplitude of chemical heterogeneities decreases with time. Clearly, for the Earth's mantle, the chemical density contrast between dense and regular material should not be too high to avoid strong stratification, but other parameters may control the formation and evolution of reservoirs of dense material.

A systematic search in the model space of thermo-chemical convection assuming an initial layer of dense material identified two important parameters that may enter a successful model of Earth's mantle (Deschamps and Tackley 2008, 2009): a moderate chemical density contrast (around $60-100 \mathrm{~kg} / \mathrm{m}^{3}$ ), to avoid chemical stratification, and a large thermal viscosity contrast $\left(\Delta \eta_{\mathrm{T}} \geq 10^{4}\right)$, which helps in maintaining large pools of dense material and opposes mixing. In models that combine these two properties, large reservoirs of dense material are maintained over periods of time comparable to the age of the Earth, inducing density and seismic velocity anomalies that are in good agreement with probabilistic tomography.

Another potentially important parameter is the Clapeyron slope of the phase change at $660 \mathrm{~km}$ depth. A negative Clapeyron slope at $660 \mathrm{~km}$, as is expected for the transformation of ringwoodite to perovskite and periclase/wüstite, prevents the dense material from massively flowing into the upper mantle. An endothermic phase change thus acts as a filter, but is not required to maintain reservoirs of dense material in the lower mantle (Deschamps and Tackley 2009). One may point out that the mineralogical transition from lower to upper mantle is complex, multiple phase transitions with different Clapeyron slopes being involved (e.g., Stixrude and Lithgow-Bertelloni 2011). A positive Clapeyron slope would affect the filtering of dense material, and larger amounts of this material may penetrate in the upper mantle. If, as suggested by mineral physics experiments (Hirose 2002), hot plumes go through an exothermic phase change (from perovskite and periclase/wüstite directly to wadsleyite and/or majoritic garnet) when entering the upper mantle, the filtering of dense material at $660 \mathrm{~km}$ would be reduced. The presence of recycled crust in plumes may further alter the value of the Clapeyron slope of the $660 \mathrm{~km}$ phase transition. However, numerical experiments indicate that the amount of dense material entrained by plumes remains compatible with the entrainment expected from the lower end values of the helium ratio $\left({ }^{4} \mathrm{He} /{ }^{3} \mathrm{He}\right)$ in Ocean Island Basalt (Sect. 15.4.1) even for a Clapeyron slope equal to zero, provided that the buoyancy ratio of the dense material is slightly larger (Deschamps et al. 2011).

\subsubsection{Stability of Primitive Reservoirs in Spherical Geometry}

To check whether the conclusions obtained in 3D Cartesian geometry are also valid in spherical geometry, we conducted additional numerical experiments with Stag YY (Tackley 2008). Spherical geometry is modeled by a set of Yin and Yang 
grids (Kageyama and Sato 2004), each grid having $64 \times 192$ azimuthal points. At each depth, this is equivalent to a spherical grid with 256 points in longitude and 128 points in latitude. We fixed the vertical resolution to 64 nodes, with grid refinement at the top and at the bottom of the shell, which allows resolution of the thermal boundary layers and the reservoirs of dense material. The ratio of the core-to-total radii is set to its terrestrial value, $f=0.55$. A phase transition is imposed at $z=660 \mathrm{~km}$ with density contrast $\Delta \rho_{660}=400 \mathrm{~kg} / \mathrm{m}^{3}$. Viscosity is allowed to vary with temperature and depth, and an additional viscosity contrast $\Delta \eta_{660}=30$ is added at the $660-\mathrm{km}$ phase transition. The viscosity is fully described by

$$
\eta(z, T)=\eta_{0}[1+29 H(z-660)] \exp \left[V_{a} \frac{z}{D}+E_{a} \frac{\Delta T_{S}}{\left(T+T_{\text {off }}\right)}+K_{\mathrm{a}} C\right],
$$

where $\eta_{0}$ is a reference viscosity, $H$ is the Heaviside step function, $D$ the mantle thickness, $\Delta T_{\mathrm{S}}$ the super-adiabatic temperature difference across the shell, and $T_{\text {off }}$ the temperature offset, which is added to the temperature to reduce the viscosity jump across the top boundary layer. The reference viscosity $\eta_{0}$ is defined at regular composition $(C=0), z=0$, and for the surface temperature of the reference adiabat (i.e., $T_{\mathrm{as}}=0.64 \Delta T_{\mathrm{S}}$ ). The viscosity variations with depth and temperature are controlled by $V_{\mathrm{a}}$ and $E_{\mathrm{a}}$, respectively, modeling the activation volume and energy. In all calculations discussed here, we fixed the value of $V_{\mathrm{a}}$ to 2.303 , which leads to a bottom-to-top depth viscosity ratio of 300 (including the viscosity jump at $660 \mathrm{~km}$, but excluding the thermally induced increase in thermal boundary layers and the increase due to adiabatic increase of temperature, which are both controlled by $\left.E_{\mathrm{a}}\right)$. We define a potential thermal viscosity contrast as $\Delta \eta_{\mathrm{T}}=\exp \left(E_{\mathrm{a}}\right)$, but due to the temperature offset, which we set to $T_{\text {off }}=0.88 \Delta T_{\mathrm{S}}$, and to the adiabatic increase of temperature, the effective top-to-bottom thermal viscosity contrast is different from $\Delta \eta_{\mathrm{T}}$. Overall, the effective contrast is smaller than $\Delta \eta_{\mathrm{T}}$ by about two orders of magnitude. Finally, the viscosity variation with composition is controlled by the parameter $K_{\mathrm{a}}$, the viscosity jump between dense and regular material being $\Delta \eta_{\mathrm{C}}=\exp \left(K_{\mathrm{a}}\right)$.

The vigor of convection is controlled by the Rayleigh number, whose definition is non-unique due to the fact that viscosity and thermodynamic parameters vary throughout the shell. Here, we prescribed a reference Rayleigh number $R a_{0}$, defined at the reference viscosity $\eta_{0}$ and surface values of the thermodynamic parameters. In all calculations, we fixed $R a_{0}$ to $3.0 \times 10^{8}$. This leads to an effective Rayleigh number (defined as the Rayleigh number at the volume average viscosity) around $10^{6}-2.0 \times 10^{6}$, depending on the case.

We used a definition of the buoyancy ratio in which the reference density increases with depth following an appropriate thermodynamical model (Tackley 1998)

$$
B_{\mathrm{z}}=\frac{\Delta \rho_{\mathrm{c}}(z)}{\alpha \rho(z) \Delta T_{\mathrm{S}}},
$$

where $\Delta \rho_{\mathrm{c}}$ is the chemical density contrast between dense and regular material, $\rho(z)$ the reference density at depth $z, \alpha$ the coefficient of thermal expansion at the 
surface of the Earth, and $\Delta T_{\mathrm{S}}$ the super-adiabatic temperature jump. Here, we used $\Delta T_{\mathrm{S}}=2500 \mathrm{~K}$. Assuming a surface temperature of $300 \mathrm{~K}$ and an adiabatic increase of $1000 \mathrm{~K}$, which is a typical for the Earth mantle, this leads to a temperature at the $\mathrm{CMB}$ of $3800 \mathrm{~K}$, i.e., at the lower edge of the most recent estimates from the phase diagram of iron (Anzellini et al. 2013), but at the higher edge of the estimates from the solidus of pyrolite (Nomura et al. 2014). Calculations performed with this definition of the buoyancy ratio are equivalent to calculations made with a buoyancy ratio that refers to the surface density, $B_{\mathrm{S}}$, but with larger value of $B_{\mathrm{S}}$. For instance, if the density increases by $50 \%$ from top to bottom, the structure obtained with a depth-dependent buoyancy ratio $B_{\mathrm{Z}}=0.20$ is equivalent to that obtained with a surface buoyancy ratio $B_{\mathrm{S}}=0.30$. The compositional field is modeled with 25 million particle tracers, leading to an average number of tracers per cell of 15, enough to model the entrainment (Tackley and King 2003). The dense material is initially distributed in a layer at the bottom of the shell, and the initial thickness of this layer is controlled by prescribing the volume fraction of dense material, $X_{\mathrm{DM}}$. Here, we fixed the volume fraction of dense material to $7 \%$ of the volume of the shell, which is a bit large compared to the estimated volume of the LLSVPs, and did an additional experiment with $X_{\mathrm{DM}}=3.5 \%$, corresponding to an upper estimate of the LLSVPs volume fraction (Sect. 15.3.3). The initial condition for temperature consists of an adiabatic profile with thin super-adiabatic boundary layers at the top and bottom of the shell, to which small random perturbations are added. With this setup, the experiment starts with a long transient phase (that can last up to 1.5-2.0 Gyr in dimensional time), during which the bottom dense layer heats up. After this phase, the evolution of the layer of dense material depends on the input parameters, mainly the buoyancy ratio and the thermal viscosity contrast (see below). In models that impose plate motions at the surface of the shell (e.g., McNamara and Zhong 2005), the transient phase is much shorter and thermo-chemical piles (if stable) form faster. Note that the experiments discussed here are not designed to model the detailed evolution of the Earth's mantle, for which accurate initial conditions are not yet known. Instead, they aim to identify the thermo-chemical structure obtained for a given set of parameters, and whether or not these structures are stable in time. Thus, time indication in our experiments should not be used to interpret early mantle evolution.

Figure 15.2 shows a snapshot of the case $B_{\mathrm{z}}=0.4$ and $X_{\mathrm{DM}}=7.0 \%$. Viscosity depends on depth, but not on temperature $\left(E_{\mathrm{a}}=0\right)$, and the Clapeyron slope of the $660-\mathrm{km}$ depth phase transition is set to zero. For this set of parameters, the system remains stratified (Fig. 15.2, plots c and d), i.e., the layer of dense material covers the entire core. This layer has substantial topography, typically around $200 \mathrm{~km}$, with highs corresponding to the foot of thermal plumes and depressions to downwellings. This layer is hot compared to the rest of the system and convection does not operate in it. Plumes are generated at its top, along a network of hot ridges (Fig. 15.2, plots a and b), but convection remains weak throughout the layer of regular material. A small fraction of dense material is, however, entrained upwards by these plumes and mixes with the regular material. This structure induces substantial chemical anomalies around the chemical discontinuity, but 


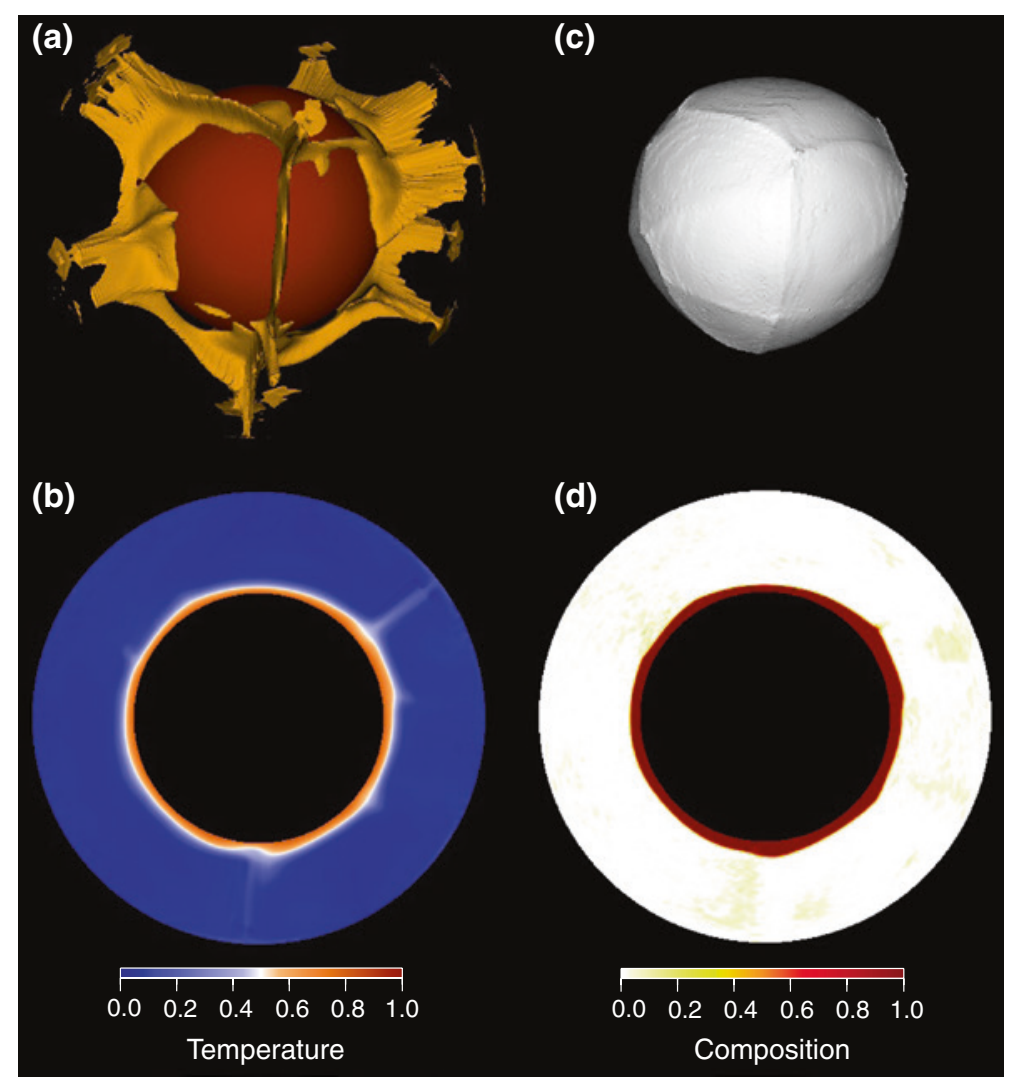

Fig. 15.2 Snapshot of a case with buoyancy ratio $B_{\mathrm{Z}}=0.4$ and $X_{\mathrm{DM}}=7.0 \%$. The viscosity jump at $660 \mathrm{~km}$ is equal to 30 , and the viscosity depends neither on the temperature $\left(E_{\mathrm{a}}=0\right.$, $\left.\Delta \eta_{\mathrm{T}}=1\right)$, nor on composition $\left(\Delta \eta_{\mathrm{C}}=1\right)$. The Clapeyron slope at $660 \mathrm{~km}\left(\Gamma_{660}\right)$ is set to zero. Snapshot is taken at non-dimensional time $t=2.12 \times 10^{-2}(9.0 \mathrm{Gyr})$. a Isosurface of the residual non-dimensional temperature with contour level $(T-\langle T\rangle)=0.05$. b Polar slice of the nondimensional temperature. c Isosurface of the composition with contour level $C=0.5$. d Polar slice of the composition

no or very weak variations elsewhere (Fig. 15.3b). The amplitude of thermal anomalies is weak, with the largest anomalies being found at the top of the dense layer (Fig. 15.3a), indicating that the thermal boundary layer is located at the top of this layer. This reduces the temperature jump between the surface and the top of the dense layer, and thus the vigor of convection in the shell.

To avoid strong layering, we decreased the buoyancy ratio to $B_{\mathrm{Z}}=0.2$ (Fig. 15.4). Other properties are similar to those of the case shown in Fig. 15.3 (in particular, viscosity does not depend on temperature). With $B_{\mathrm{z}}=0.2$, the initial layer of dense material is unstable and quickly mixes with the regular material (Fig. 15.4, plots c and d). As a result, large-scale chemical anomalies are small 

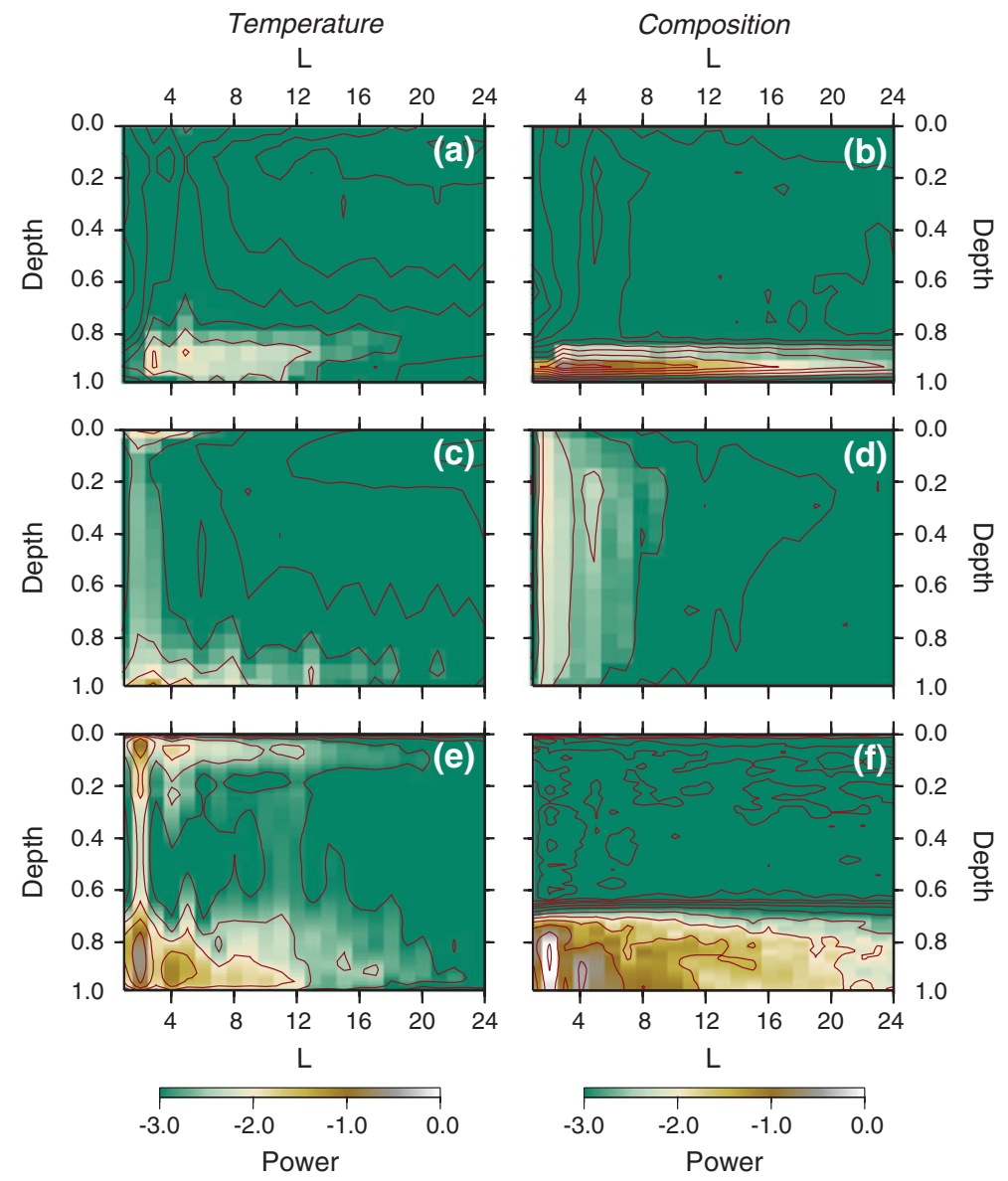

Fig. 15.3 Spectral heterogeneity map (SHM) of the anomalies in temperature (left column) and composition (right column) for three cases. Top row buoyancy ratio $B_{\mathrm{Z}}=0.4, X_{\mathrm{DM}}=7 \%$, $E_{\mathrm{a}}=0\left(\Delta \eta_{\mathrm{T}}=1\right)$, and $\Gamma_{660}=0$, corresponding to the snapshot represented in Fig. 15.2. Middle row $B_{\mathrm{Z}}=0.2, X_{\mathrm{DM}}=7 \%, E_{\mathrm{a}}=0\left(\Delta \eta_{\mathrm{T}}=1\right)$, and $\Gamma_{660}=0$, corresponding to the snapshot shown in Fig. 15.4. Bottom row $B_{\mathrm{Z}}=0.2, X_{\mathrm{DM}}=7 \%, E_{\mathrm{a}}=20.723\left(\Delta \eta_{\mathrm{T}}=10^{9}\right)$, and $\Gamma_{660}=-2.5 \mathrm{MPa} / \mathrm{K}$, corresponding to the snapshot represented in Fig. 15.5

throughout the mantle (Fig. 15.3d). At large scale, the mantle therefore appears homogeneous. Four large plumes are generated from a thin thermal boundary layer at the bottom of the shell (Fig. 15.4, plots a and b), inducing moderate thermal anomalies at the bottom and at the top of the system (Fig. 15.3c).

The model shown in Fig. 15.5 was obtained for $E_{\mathrm{a}}=20.723\left(\Delta \eta_{\mathrm{T}}=10^{9}\right.$, leading to an effective thermal viscosity contrast around $3.0 \times 10^{5}$ ). In addition, we imposed an endothermic phase transition at $660 \mathrm{~km}$ depth, with a Clapeyron slope $\Gamma=-2.5 \mathrm{MPa} / \mathrm{K}$. Other properties are similar to those of the cases 


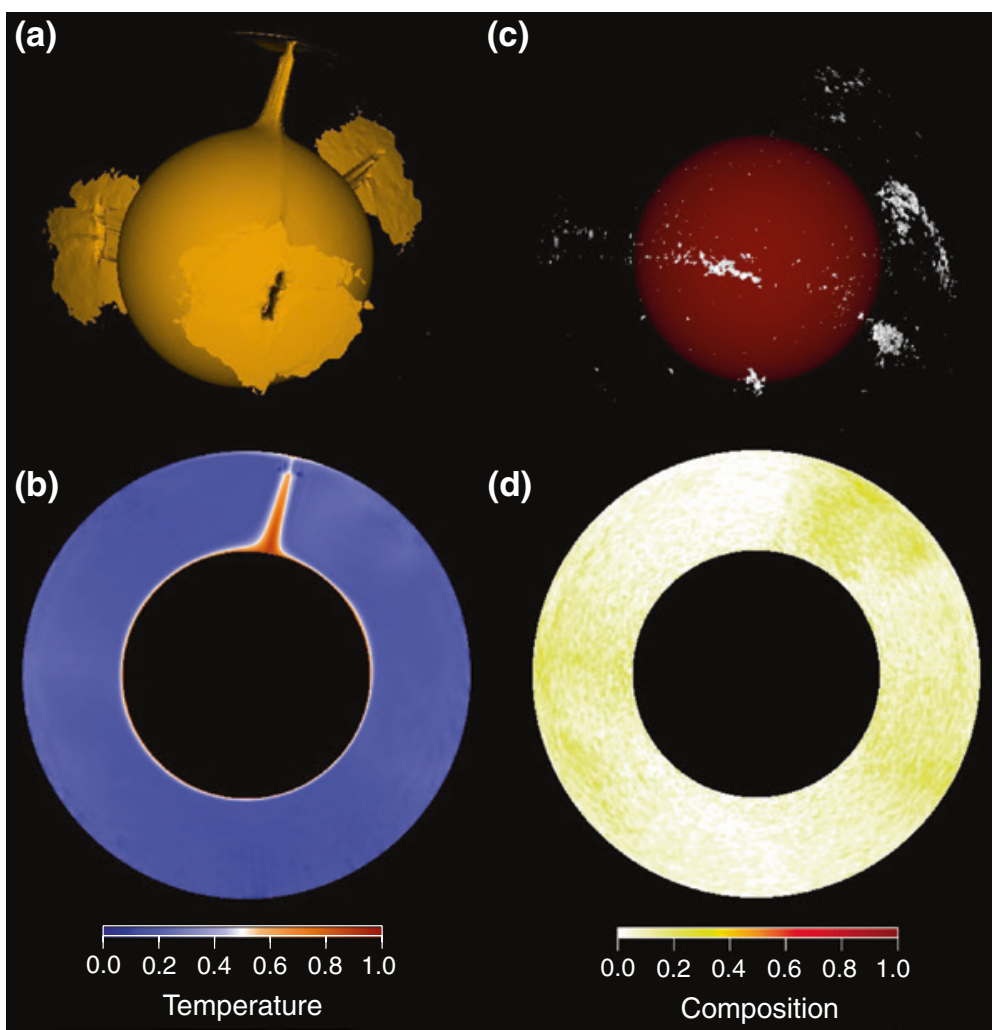

Fig. 15.4 Snapshot of the case $B_{\mathrm{z}}=0.2, X_{\mathrm{DM}}=7.0 \%, E_{\mathrm{a}}=0\left(\Delta \eta_{\mathrm{T}}=1\right)$, and $\Gamma_{660}=0$. The viscosity jump at $660 \mathrm{~km}$ is equal to 30 , and the viscosity does not depend on composition $\left(\Delta \eta_{\mathrm{C}}=1\right)$. Snapshot is taken at non-dimensional time $t=1.06 \times 10^{-2}(4.5 \mathrm{Gyr})$. a Isosurface of the non-dimensional temperature with contour level $T=0.55$. b Polar slice of the non-dimensional temperature. $\mathbf{c}$ Isosurface of the composition with contour level $C=0.5$. d Polar slice of the composition

shown in Figs. 15.2 and 15.4. For this set of parameters, we observe two large reservoirs of dense material culminating at $\sim 1000 \mathrm{~km}$ above the CMB (Fig. 15.5, plots $\mathrm{c}$ and $\mathrm{d}$ ). These reservoirs remain stable and induce strong lateral chemical anomalies dominated by spherical harmonic degree 2 in the bottom part of the shell (Fig. 15.3f). In contrast, the rest of the shell is chemically homogeneous at large scale. Small-scale heterogeneities, due to entrainment of dense material by plumes, are, however, present locally. Plumes are generated along hot ridges at the top of the reservoirs and rise up to the surface (Fig. 15.5, plots a and b). Note that they spread beneath the $660 \mathrm{~km}$ and that secondary thinner plumes are generated on the top side of this phase transition. There is also evidence for plume interaction with mantle horizontal flow below the $660-\mathrm{km}$ phase transition (top left and bottom right quadrants of Fig. 15.5b). The roots of these plumes are distributed 


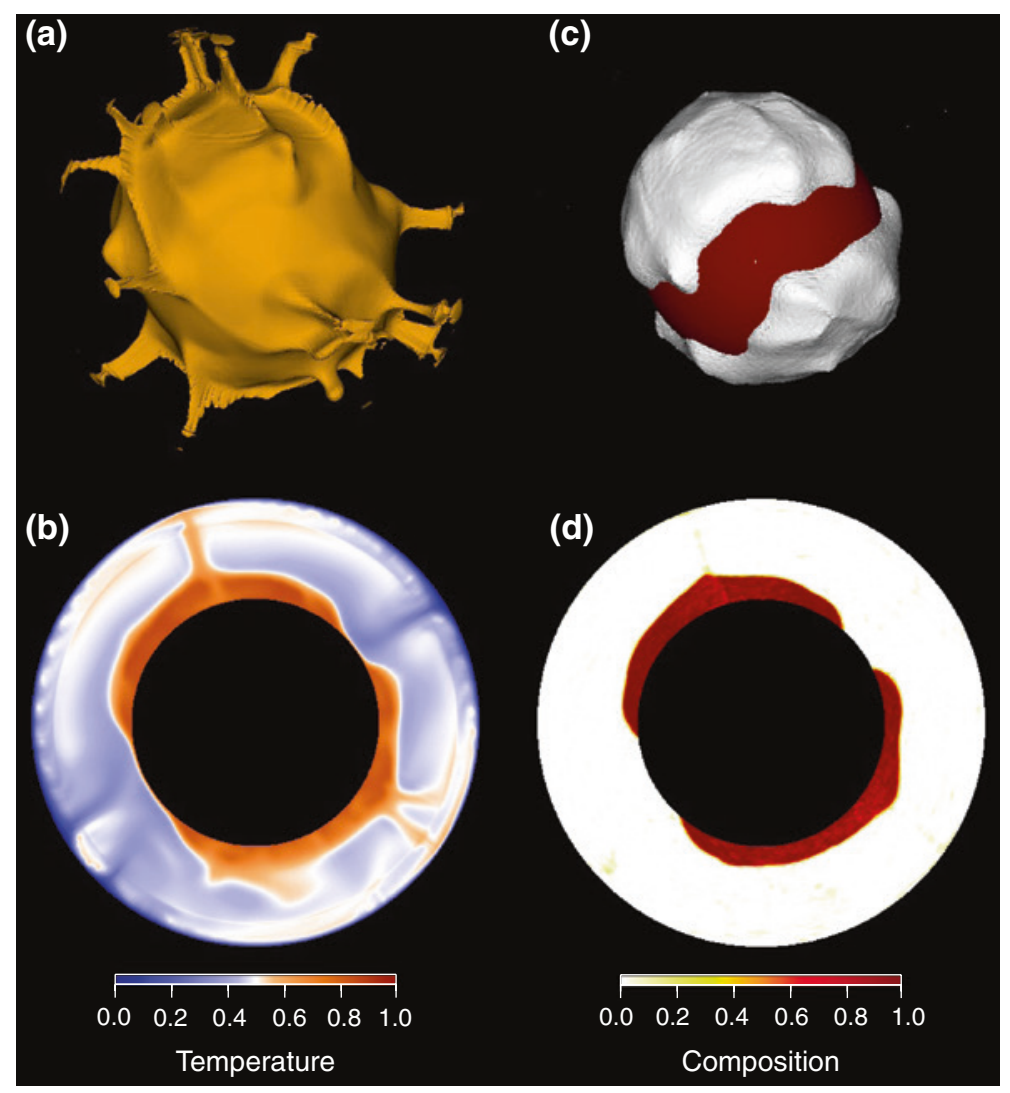

Fig. 15.5 Snapshot of the case $B_{\mathrm{z}}=0.2, X_{\mathrm{DM}}=7.0 \%, E_{\mathrm{a}}=20.723\left(\Delta \eta_{\mathrm{T}}=10^{9}\right)$, and $\Gamma_{660}=-2.5 \mathrm{MPa} / \mathrm{K}$. The viscosity jump at $660 \mathrm{~km}$ is equal to 30 , and the viscosity does not depend on composition $\left(\Delta \eta_{\mathrm{C}}=1\right)$. Snapshot is taken at non-dimensional time $t=3.18 \times 10^{-2}$ (13.5 Gyr). a Isosurface of the non-dimensional temperature with contour level $T=0.55$. b Polar slice of the non-dimensional temperature. $\mathbf{c}$ Isosurface of the composition with contour level $C=0.5$. $\mathbf{d}$ Polar slice of the composition

throughout the surface of the reservoirs, including at their borders. By contrast, we do not observe plumes originating from outside the reservoirs of dense material. Plumes entrain small amounts of dense material (see, e.g., the top left quadrant of Fig. 15.5d), thus eroding the dense reservoirs. Importantly, this erosion is very small, which prevent reservoirs from being completely entrained within a reasonable time (i.e., comparable to the age of the Earth). Downwellings are located between the reservoirs, suggesting that they strongly interact with the initial dense layer by deflecting it and pushing it away. This thermal structure induces strong thermal anomalies at the bottom of the shell and below its surface, where plume heads spread (Fig. 15.3e). 
3D Cartesian models further indicated that the chemical viscosity contrast has an influence on the shape of reservoirs. With increasing chemical viscosity contrast, these reservoirs are thicker, cover a smaller area, and have steeper edges (McNamara and Zhong 2004; Deschamps and Tackley 2009). Additional calculations in spherical geometry confirm these trends ( $\mathrm{Li}$ et al. 2014a).

Overall, the conclusions obtained in 3D Cartesian geometry regarding the stability and survival of reservoirs of dense material (Sect. 15.3.1) are also valid in spherical geometry. Interestingly, the chemical structure of models that include a moderate buoyancy ratio and strong thermal viscosity contrast is dominated by spherical harmonic degree 2, as in the case of the Earth's mantle, assuming that the LLSVPs observed by seismic tomography are thermo-chemical structures.

\subsubsection{Additional Constraints and Models}

In the model shown in Fig. 15.5, we fixed the volume fraction of dense material to $7 \%$, which is too large for comparison with the Earth's mantle. As a result, the reservoirs are significantly larger (both in lateral extension and thickness) than the LLSVPs observed in the Earth's mantle. The volume of LLSVPs is not very well constrained. A rough estimate from HMSL-S06 (Houser et al. 2008) leads to a volume fraction (with respect to entire mantle) of around $4.0 \%$. Burke et al. (2008) defined the LLSVP boundaries as the $-1.0 \%$ contour of the $\operatorname{dn} V_{\mathrm{S}}$ maps from the SMEAN model and found a volume fraction of $1.6 \%$. Estimates from the non-Gaussian anomaly in the $\operatorname{dn} V_{\mathrm{S}}$ distribution histograms gives values in the range 1.7-2.4\% (Hernlund and Houser 2008). Therefore, models of convection suitable for the Earth's mantle should have a fraction of dense material around 2-4\%. Interestingly, numerical experiments with a volume fraction of dense material in the range $2.5-15 \%$ (Li et al. 2014a) show that decreasing the volume fraction of dense material does not alter the long-term stability of these reservoirs. In addition, these experiments indicate that the distribution of plumes is sensitive to the volume fraction of the dense material. For volume fractions around $5 \%$ and smaller, plumes are mostly distributed on the edges of the reservoirs of dense material ( $\mathrm{Li}$ et al. 2014a), whereas for larger volume fractions, they are more evenly distributed throughout the surface of these reservoirs. As an example, Fig. 15.6 shows a case with $X_{\mathrm{DM}}=3.5 \%$, other parameters being similar to those in Fig. 15.5, except the chemical viscosity contrast, which is set to $\Delta \eta_{\mathrm{C}}=32$. The distribution of plumes along the edge of the reservoirs of dense material is globally consistent with the observation that the position of hot spots and the reconstructed positions of the large igneous provinces (LIPs) at the time they were active are preferentially located above the edges of LLSVPs (Burke and Torsvik 2004; Torsvik et al. 2008). Note that in these reconstructions, a few active hot spots and reconstructed LIPs are located within the LLSVPs. Furthermore, a recent study (Austermann et al. 2014) suggests that the correlation between LIP locations and LLSVP margins is statistically not significant and that observations 


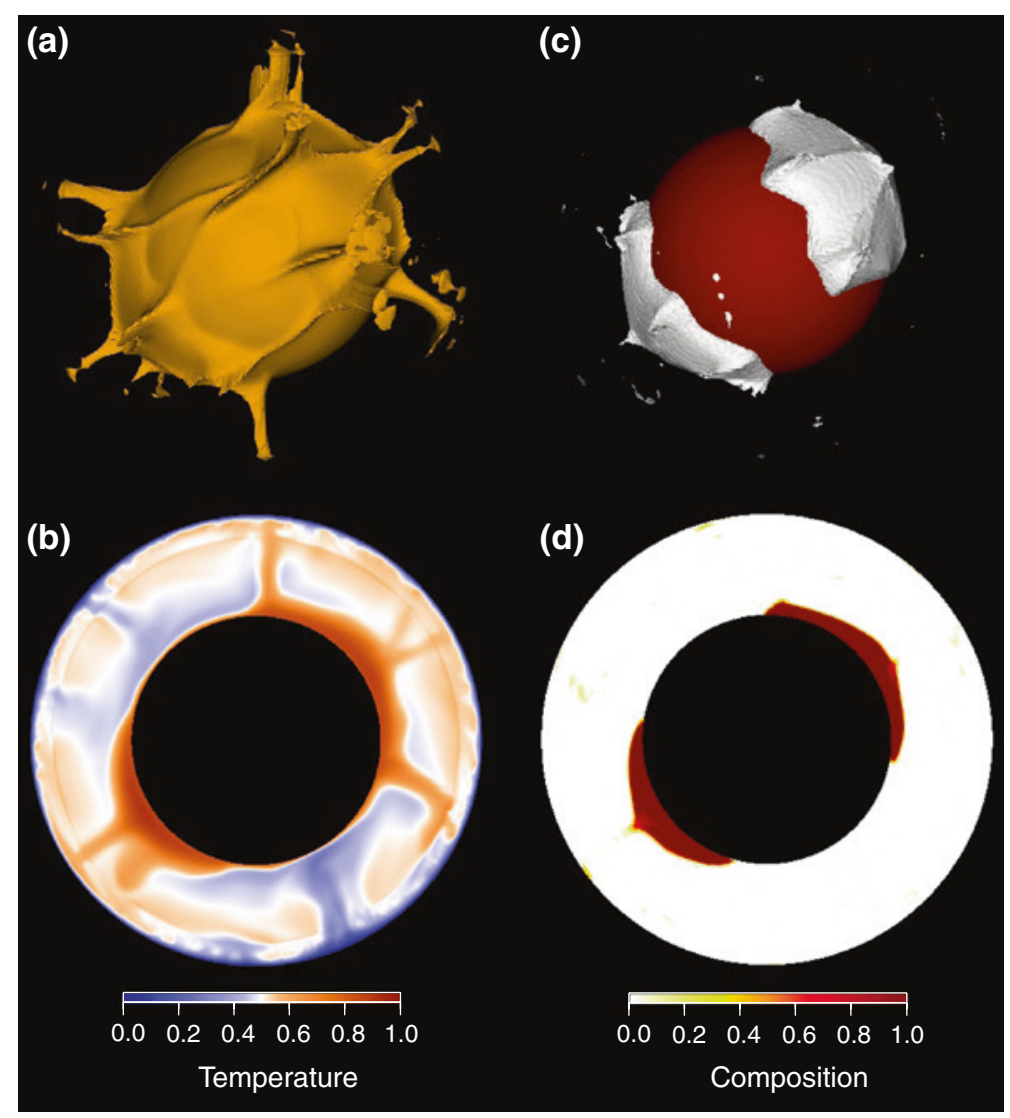

Fig. 15.6 Snapshot of the case $B_{\mathrm{z}}=0.20, X_{\mathrm{DM}}=3.5 \%, E_{\mathrm{a}}=20.723\left(\Delta \eta_{\mathrm{T}}=10^{9}\right)$, and $\Gamma_{660}=-2.5 \mathrm{MPa} / \mathrm{K}$. The viscosity jump at $660 \mathrm{~km}$ is equal to 30 , and the chemical viscosity ratio is $\Delta \eta_{\mathrm{C}}=32$. Snapshot is taken at non-dimensional time $t=3.18 \times 10^{-2}(13.5 \mathrm{Gyr})$. a Isosurface of the non-dimensional temperature with contour level $T=0.55$. b Polar slice of the non-dimensional temperature. c Isosurface of the composition with contour level $C=0.5$. d Polar slice of the composition. Note that the view angle is different compared to that for Fig. 15.5

are also compatible with plumes originating from the LLSVP interiors. Finally, due to thermal winds and plume spreading beneath the $660-\mathrm{km}$ discontinuity and beneath the surface (plots a and b in Figs. 15.5 and 15.6), the surface locations of plumes may be slightly shifted compared to the position of their root.

Because it controls the increase of density with pressure (as, for instance, in Birch-Murnaghan equation of state), the bulk modulus may influence the shape and stability of dense reservoirs (Tan et al. 2011). Density increases more rapidly with depth for material having high values of the bulk modulus. In addition, a high bulk modulus reduces the adiabatic increase of temperature, hence decreasing the thermal buoyancy of reservoirs. Models in which the bulk modulus of the dense material is larger than that of the surrounding fluid can remain stable for 
billions of years (Tan et al. 2011). Furthermore, these reservoirs have sharp edges, in agreement with travel and waveforms observations (Sect. 15.2), and plumes are preferentially located at their edges. Tan et al. (2011) have further investigated the interactions between downwellings and primitive reservoirs and found that downwellings tend to push plumes toward the reservoirs.

The models of convection discussed earlier in this section have a free slip mechanical surface boundary. As they reach the bottom of the shell, the downwellings generated in these models interact with the dense layer by pushing it away. In that sense, downwellings control the locations of the reservoirs of dense material. However, a detailed comparison with the present day structure of the Earth mantle requires the imposition of surface plate motions (e.g., using plate tectonic reconstruction models), which allows a better description of the interactions between downwellings and thermo-chemical piles. In models that use such reconstructions (McNamara and Zhong 2005; Zhang et al. 2010; Bower et al. 2013), plumes are preferentially generated at the edges of the dense reservoirs, in agreement with reconstructions of LIPs positions (Burke and Torsvik 2004; Torsvik et al. 2008). These models further explain the rounded shape of the Pacific LLSVP, and details of the African LLSVP observed by travel time data and seismic waveform modeling, in particular its sharp edges (Sect. 15.2).

The models discussed in this section consider only one source of chemical heterogeneity. A full description of the Earth's mantle structure and dynamics may, however, require two sources, reservoirs of dense primitive material (i.e., resulting from early mantle differentiation), and recycled oceanic crust entrained in the lower mantle by slabs. We further discuss this point in Sect. 15.4.1.

\subsection{The Nature of the Lower Mantle Chemical Heterogeneities}

\subsubsection{Early Differentiated Material Versus Recycled MORB}

The nature and origin of chemical heterogeneity detected by seismological observations is still a matter of debate. Two end-member hypotheses, the recycling of oceanic crust (MORB) and the survival of reservoir(s) of primitive or early differentiated material, are usually advocated and are both dynamically feasible.

The recycling of oceanic crust carried by slabs to the deep mantle is a straightforward source of heterogeneity. Seismic tomography clearly shows that slabs can penetrate to the deep mantle and sink down to the CMB (Fukao et al. 2001; Kárason and van der Hilst 2000; van der Hilst et al. 1997). Dynamically, numerical models of thermal convection have established that the endothermic phase transition at $660 \mathrm{~km}$ is not impermeable to downwelling slabs (e.g., Christensen and Yuen 1985; Machetel and Weber 1991; Tackley et al. 1993, 1994). Thus, stacking of the MORB component of slabs in the deep mantle may result in reservoirs of dense, recycled material. This hypothesis has been tested by numerical models (Christensen 1989; Christensen and Hofmann 1994) and laboratory 
experiments (Olson and Kincaid 1991), but recent models indicate that only small amount of oceanic crust may accumulate at the bottom of the mantle (Li and McNamara 2013). The production and recycling of MORB have also been modeled in a 2D-cylindrical shell and coupled with core evolution (Nakagawa and Tackley 2004, 2005b) and with the presence of the post-perovskite phase transition (Nakagawa and Tackley 2005a). These studies pointed out that the formation of pools of dense material and their shape depends on core properties (Nakagawa and Tackley 2005b), on the buoyancy ratio of MORB (Nakagawa and Tackley 2004), and on the Clapeyron slope of the post-perovskite phase transition (Nakagawa and Tackley 2005a). Models that include self-consistent mineralogy (Nakagawa et al. 2010) show that the shape and stability of the reservoirs of segregated MORB depend on the assumed MORB composition in main oxides. A MORB that is richer in $\mathrm{FeO}$ segregates more readily to a stable dense layer around the core. Finally, it has been suggested that recycled MORB may be episodically incorporated in LLSVPs (Tackley 2012). 2D Cartesian models of convection including two sources of heterogeneities have recently tested this hypothesis ( $\mathrm{Li}$ et al. 2014b). These simulations indicate that small amounts of recycled MORB are injected in the piles of primitive material and subsequently entrained upwards by the plumes generated at the top of the piles. If the MORB is less dense than the primordial material, however, then it tends to accumulate above the dense material (Nakagawa and Tackley 2014).

The presence of an undegassed, isolated reservoir hidden in the deep mantle has long been advocated by geochemists to be one of the sources of ocean island basalt (OIB) (e.g., Farley et al. 1992; Hofmann 1997; Stuart et al. 2003). A key geochemical observation is the strong dispersion of the isotopic helium ratio $\left({ }^{4} \mathrm{He} /{ }^{3} \mathrm{He}\right)$ in $\mathrm{OIB}$, ranging from 15,000 to 200,000 . This suggests that the plumes at the origin of OIB sample several sources in the mantle. The low values $(<30,000)$ of OIB helium ratio further indicate that one of the reservoirs sampled by OIB plumes is undegassed, and its lowest value (around 15,000) imposes a constraint on the maximum amount of primitive material entrained by plumes (Allègre and Moreira 2004). Other geochemical hints include the Argon budget (Allègre et al. 1996), and the high values of the ${ }^{143} \mathrm{Nd} /{ }^{144} \mathrm{Nd}$ ratio measured in the Baffin Island and western Greenland lavas (Jackson et al. 2010), which suggest that these rocks were extracted from an early-formed $(\sim 4.5 \mathrm{Gyr})$ mantle reservoir. Additional results for the $\mathrm{Sm}-\mathrm{Nd}$, Lu-Hf, and $\mathrm{Rb}-\mathrm{Sr}$ systems suggest that Earth accreted from non-chondritic material depleted in incompatible elements, and that pristine material may be preserved in the deep mantle until now (see Caro, this volume). Numerical models showed that in models including a moderate buoyancy ratio and a large thermal viscosity contrast, the entrainment of dense material by plumes is less than $10 \%$ (Deschamps et al. 2011), in agreement with geochemical estimates based on mass balance calculations (Allègre and Moreira 2004). An endothermic phase transition at $660 \mathrm{~km}$ further reduces the entrainment of dense material in the upper mantle, but plumes may instead go through an exothermic transition as they enter the upper mantle (Hirose 2002; Sect. 15.3.1). The large values $(>100,000)$ of the OIB helium ratio suggest that another reservoir sampled by OIB plumes is recycled oceanic crust (e.g., Hofmann 1997). Again, 
this is consistent with the numerical simulations of Li et al. (2014b), which show that both primitive material and recycled MORB may be entrained by the plumes rising from the top of the reservoirs of dense material.

Several mechanisms have been proposed for the early partial differentiation of the Earth's mantle, including fractional crystallization of a regular magma ocean (Solomatov and Stevenson 1993; Solomatov 2007), crystallization of a basal magma ocean (Labrosse et al. 2007), which also explains the ultra-low seismic velocity zones (ULVZ) observed locally at the bottom of the mantle (Garnero and Helmberger 1995; Williams and Garnero 1996), 'upside-down' differentiation (Lee et al. 2010), which consists of the formation, crystallization, and sinking of dense liquids in the upper mantle during the Earth's first billion year, and the recycling of a primitive crust (Tolstikhin et al. 2006), which is supported by geochemical data (Boyet and Carlson 2006; Caro et al. 2003, 2004) and numerical models of convection (van Thienen et al. 2004, 2005). Alternatively, models of mantle composition based on E-chondrite predict that the composition in main oxides of the lower mantle is different from that of the upper mantle (Javoy et al. 2010). Kaminski and Javoy (2013) have further shown that a two-stage scenario of Earth formation, consisting of the formation of a proto-core at low pressure and temperature (around $50 \mathrm{GPa}$ and $3500 \mathrm{~K}$, respectively) followed by a giant impact, can explain the chemical heterogeneities observed in the lowermost mantle (see also Kaminski and Javoy, this volume).

Mineral physics experiments (Nomura et al. 2011) predict that a primitive reservoir resulting from the crystallization of a basal magma ocean would be richer in iron. It is worth noting that the Fe/Mn ratio in Hawaiian lavas indicates that the source region of the Hawaiian plume, which may be located in the lowermost mantle, is enriched in iron (Humayun et al. 2004). E-chondrite models of Earth's mantle composition also imply that reservoirs of primitive material should be enriched in iron and silicate (Javoy et al. 2010). Interestingly, the compositional anomalies inferred from probabilistic tomography (Trampert et al. 2004; Mosca et al. 2012) show that LLSVPs are enriched in iron (partitioned between Fe-perovskite and wüstite) and silicate (in perovskite). Furthermore, seismic sensitivities calculated from a coherent mineral physics database (Stixrude and Lithgow-Bertelloni 2011) indicate that LLSVPs are better explained by material enriched in iron (by about $3.0 \%$ ) and in perovskite (by about $20 \%$ ) than by recycled MORB, unless these MORB are hotter than the surrounding mantle by $1000 \mathrm{~K}$ or more (Deschamps et al. 2012). We further detail this point in Sect. 15.4.2.

\subsubsection{Seismic Signatures of Differentiated Material and Recycled MORB}

Seismic signatures provide key information about the nature of the chemical heterogeneities in the deep mantle. Linking observed seismic velocity anomalies to thermo-chemical distributions requires knowledge of seismic sensitivities to 
temperature and various chemical components. These sensitivities can be derived from an appropriate equation of state modeling and available mineral physics database. A Monte Carlo search allows accounting for various sources of uncertainties, including uncertainties in the mantle thermo-chemical reference model, and in the thermo-elastic and thermodynamic properties of the mantle minerals (Trampert et al. 2001; Deschamps and Trampert 2003). Alternatively, algorithms minimizing the Gibbs free energy of petrological aggregates, e.g., Perple_X (Connolly 2005), provide the mineralogical composition and thermo-elastic properties for this aggregate at given pressure, temperature, and composition in main oxides.

Seismic sensitivities to various chemical components (Trampert et al. 2001; Deschamps and Trampert 2003; Deschamps et al. 2012) show that an enrichment in iron induces a decrease in both shear-wave and bulk-sound velocities, whereas an enrichment in silicate induces an increase in bulk-sound velocity but leaves shear-wave velocity unchanged. Sensitivities to MORB further indicate that both $V_{\mathrm{S}}$ and $V_{\Phi}$ increase with increasing MORB fraction throughout the lower mantle. As a result, a combined enrichment in iron and silicate is a good candidate to explain LLSVPs and the anti-correlation between $V_{S^{-}}$and $V_{\Phi^{-a n o m a l i e s}}$. One may point out that because MORB is naturally richer in iron, an increase in the MORB fraction should have a seismic signature similar to that of a material enriched in iron (distributed between periclase and perovskite). An important observation, however, is that the effect of iron on $V_{\mathrm{S}}$ and $V_{\Phi}$ is much more pronounced in periclase (Kung et al. 2002) than in perovskite (Kiefer et al. 2002). Because periclase is not present in MORB, the seismic signature of an increase in the global volume fraction of iron on seismic velocities is significantly different from that of an increase in the volume fraction of MORB.

Figure 15.7 shows frequency histograms of shear-wave $\left(\mathrm{d} \ln V_{\mathrm{S}}\right)$ and bulk-sound $\left(\mathrm{d} \ln V_{\Phi}\right)$ velocity anomalies induced either by high-pressure MORB or by material enriched in iron and perovskite in the deep (2710-2890 km) mantle. Seismic velocity anomalies for MORB and material enriched in iron and perovskite are calculated by

$$
\begin{gathered}
\mathrm{d} \ln V=\frac{\partial \ln V}{\partial T} \mathrm{~d} T+\frac{\partial \ln V}{\partial X_{\mathrm{MORB}}} \mathrm{d} X_{\mathrm{MORB}}, \\
\text { and } \quad \mathrm{d} \ln V=\frac{\partial \ln V}{\partial T} \mathrm{~d} T+\frac{\partial \ln V}{\partial X_{\mathrm{Pv}}} \mathrm{d} X_{\mathrm{Pv}}+\frac{\partial \ln V}{\partial X_{\mathrm{Fe}}} \mathrm{d} X_{\mathrm{Fe}},
\end{gathered}
$$

respectively, where $V$ stands for $V_{\mathrm{S}}$ or $V_{\Phi}$, and $X_{\mathrm{MORB}}, X_{\mathrm{Pv}}$, and $X_{\mathrm{Fe}}$ are the volume fractions of MORB, perovskite, and iron. The seismic sensitivities, $\partial \ln V / \partial X$, are from Deschamps et al. (2012). These sensitivities were obtained from a selfconsistent mineral physics database (Stixrude and Lithgow-Bertelloni 2011) and an equation of state modeling that takes into account various sources of uncertainties in the thermo-elastic data and reference thermo-chemical model (Cobden et al. 2012). Seismic sensitivities are given as probability density functions (pdf) (rather than single values) with nearly Gaussian distributions. As a result, for fixed values 
of the temperature $(\mathrm{d} T)$ and compositional ( $\mathrm{d} X_{\mathrm{MORB}}$ or $\mathrm{d} X_{\mathrm{pv}}$ and $\mathrm{d} X_{\mathrm{Fe}}$ ) anomalies, the seismic velocity anomalies calculated by Eqs. (15.3) and (15.4) are also pdf and can be plotted as frequency histograms. The strong dispersion in the frequency histograms calculated for MORB results from the strong dispersion in the MORB composition in main oxides. For instance, the $\mathrm{FeO}$ fraction in MORB can vary by as much as 0.07 , depending on the sample. For a temperature anomaly of $400 \mathrm{~K}$, material enriched in iron and perovskite results in $\mathrm{d} \ln V_{\mathrm{S}}$ and $\mathrm{d} \ln V_{\Phi}$ around -2.0 and $0.5 \%$, respectively (Fig. $15.7 \mathrm{~g}$ ), in good agreement with the values observed in LLSVPs. By contrast, the dln $V_{\mathrm{S}}$ predicted by high-pressure MORB are too small in amplitude (around $-0.5 \%$ ), compared to those in LLSVPs. Seismic signatures of material enriched in iron and perovskite fit well LLSVP anomalies up to temperature excess around $700 \mathrm{~K}$ (Deschamps et al. 2012). At higher temperatures (plots $\mathrm{d}$ and $\mathrm{h}$ in Fig. 15.7), high-pressure MORB explains the $\mathrm{d} \ln V_{\mathrm{S}}$ observed in LLSVPs better, but induces negative $\mathrm{d} \ln V_{\Phi}$ anomalies, in contradiction with seismic tomography (Ishii and Tromp 1999; Masters et al. 2000; Trampert et al. 2004; Houser et al. 2008). High-pressure MORB colder than the surrounding mantle by $400 \mathrm{~K}$ induces $\mathrm{d} \ln V_{\mathrm{S}}$ and $\mathrm{d} \ln V_{\Phi}$ around 1.0 and $0.5 \%$, respectively (Fig. 15.7b). These values agree well with values of $d \ln V_{\mathrm{S}}$ and $\mathrm{d} \ln V_{\Phi}$ observed by HMSL_SP06 (Houser et al. 2008) beneath the Japan subduction zone, where continuous high shear-wave velocities are observed down to the CMB (Ritsema and van Heijst 2000), and beneath Peru, Bolivia, and western Brazil. This result is consistent with the modeling of Tan et al. (2002). High-pressure MORB with larger temperature deficit (1000 K and more) induces $\mathrm{d} \ln V_{\mathrm{S}}$ around $3.0 \%$ (Fig. 15.7a), which is too large compared to the value observed at the expected location of stacked slabs.

Figure 15.7 further illustrates the trade-off existing between temperature and composition, since LLSVPs may be explained by either warm (hotter than the surrounding mantle by 400-700 K) material enriched in iron and perovskite, or very hot (hotter than the surrounding mantle by $1000 \mathrm{~K}$ ) recycled MORB. In the latter case, it should, however, be noted that the predicted values of $\operatorname{dn} V_{\Phi}$ in LLSVPs are too small in amplitude, compared to those observed by seismic tomography. There are no direct measurements of the amplitude of the lateral variations in temperature at the bottom of the mantle. Recent estimates suggest peak-to-peak variations around $1500 \mathrm{~K}$ (Tackley 2012), i.e., a temperature excess (compared to average mantle) around $750 \mathrm{~K}$. Another hint is given by estimates of the temperature excess in plumes, around 250-300 K (Campbell and Griffiths 1990). Such low values are consistent with the hypothesis that plumes originate from chemically distinct reservoir of dense material. For a compositional excess density between 2.0 and $5.0 \%$, a $250-300 \mathrm{~K}$ temperature excess in plumes implies temperature anomalies at the foot of the plume between 600 and $800 \mathrm{~K}$ (Farnetani 1997). Following this estimate, and according to Fig. 15.7, LLSVPs are better explained by warm material enriched in iron and perovskite than by hot recycled MORB. Note that other effects may contribute to reduce the temperature excess 

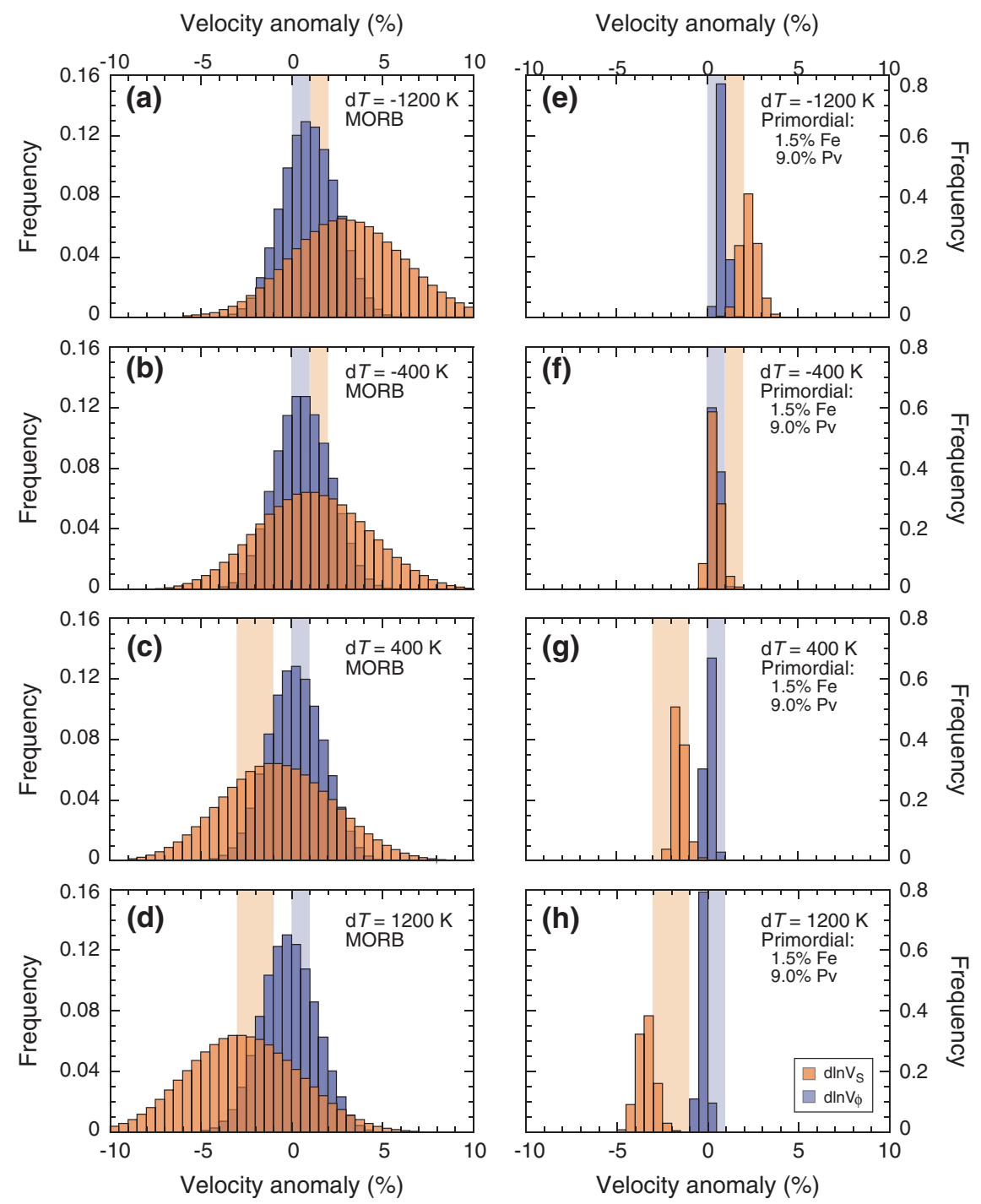

Fig. 15.7 Frequency histograms of shear-wave velocity (orange) and bulk-sound velocity (blue) anomalies for high-pressure MORB (left column), and for a material enriched (compared to the horizontally averaged mantle) in iron by $1.5 \%$ and in $(\mathrm{Mg}, \mathrm{Fe}$ )-perovskite by $9.0 \%$ (right column). Four values of the temperature anomaly (compared to average mantle) are considered, from top to bottom $\mathrm{d} T=-1200 \mathrm{~K}, \mathrm{~d} T=-400 \mathrm{~K}, \mathrm{~d} T=400 \mathrm{~K}$, and $\mathrm{d} T=1200$. Shaded vertical bands in plots (a-b) and (e-f) indicate that typical values of seismic velocities observed beneath Central America and South America, where subducted slab is assumed to be present. Shaded vertical bands in plots (c-d) and ( $\mathbf{g}-\mathbf{h})$ indicate typical values of seismic velocities in LLVSPs. Calculations are made in the layer $2710-2890 \mathrm{~km}$, corresponding to the lowermost layer of tomographic model HMSL-SP06 (Houser et al. 2008) 
in plumes, including internal heating (Parmentier et al. 1994), adiabatic cooling (Albers and Christensen 1996; Bunge 2005), and lateral diffusion (Mittelstaedt and Tackley 2005).

\subsection{The Role of the Post-perovskite Phase}

A major mineral physics discovery of the past decade is the post-perovskite phase transition (Murakami et al. 2004; Oganov and Ono 2004; Tsuchiya et al. 2004a). At pressure of $125 \mathrm{GPa}$ and temperature of $2500 \mathrm{~K}, \mathrm{MgSiO}_{3}$ perovskite transforms to a post-perovskite phase. This phase transition has a large Clapeyron slope, in the range 8-10 MPa/K (Oganov and Ono 2004; Tsuchiya et al. 2004a), and even larger according to more recent estimates (Tateno et al. 2009). Furthermore, the composition is likely influencing the pressure at which the transition occurs. Experimental (Mao et al. 2004) and theoretical (Caracas and Cohen 2005) studies suggest that iron-rich perovskite transforms at lower pressures $(110 \mathrm{GPa})$ than pure $\mathrm{MgSiO}_{3}$ perovskite. Ohta et al. (2008) observed that compared to pure $\mathrm{MgSiO}_{3}$ perovskite, the transition to post-perovskite occurs at similar pressure for a pyrolitic composition, and at slightly lower pressures for a MORB composition. Mineral physics experiments have also explored the iron partitioning between perovskite and post-perovskite. Andrault et al. (2009) found that for a temperature of $3300 \mathrm{~K}$, perovskite and post-perovskite may coexist throughout the lowermost mantle, but that post-perovskite would be depleted in iron compared to perovskite, with iron partitioning between perovskite and post-perovskite around 4.2. Sinmyo et al. (2011) reached a similar conclusion and showed that during the perovskite to post-perovskite phase transition, iron changes its valence from $\mathrm{Fe}^{3+}$ to $\mathrm{Fe}^{2+}$ and preferentially partitions to ferro-periclase.

Due to the large Clapeyron slope of the phase transition to post-perovskite, the depth at which this transition occurs is expected to strongly vary laterally, depending on the temperature. In cold regions, perovskite should transform to post-perovskite at relatively shallow depths (an effect that may be enhanced if these cold regions are enriched in MORB), whereas in hot regions it may not transform at all. In cold and warm regions, double crossings are expected to happen (Hernlund et al. 2005), the thickness of the post-perovkite lens depending on the temperature at the CMB. On seismograms, the transition to post-perovskite results in precursors to core-reflected ScS waves (Hernlund et al. 2005). A double crossing induces a weaker intermediate arrival on seismograms. Waves diffracted at the CMB provide additional hints for the presence of post-perovskite. A recent study showed that post-perovskite is needed to explain shear- and compressional-wave velocity anomalies derived from $\mathrm{P}_{\text {diff }}$ and $\mathrm{S}_{\text {diff }}$ arrivals (Cobden et al. 2012). More details on the seismic detection of the post-perovskite may be found in Cobden et al. (this volume).

The thermo-elastic properties of post-perovskite are partly available (Tsuchiya et al. 2004b; Caracas and Cohen 2007; Mao et al. 2007; Oganov and Ono 2004; Stackhouse et al. 2005; Stackhouse and Brodholt 2007) and can be used to 
calculate seismic velocity and density sensitivities. These data indicate that shearwave velocity in post-perovskite is larger than in perovskite by about $2 \%$, but that bulk-sound velocity is slightly lower, by less than $1 \%$. The phase transition to post-perovskite is a good candidate for the $\mathrm{D}^{\prime \prime}$ discontinuity (Wookey et al. 2005), which has been detected in many locations (e.g., beneath North Siberia and beneath Alaska), but is not ubiquitous. Its elevation above the CMB varies between about 150 and $400 \mathrm{~km}$, and the relative increase in $V_{\mathrm{S}}$ ranges from 2 to $4 \%$ (Wysession et al. 1998). By contrast, because an excess in post-perovskite (compared to the average pyrolitic mantle) would result in positive $V_{\mathrm{S}}$ anomalies, post-perovskite is unlikely to explain LLSVPs, unless these regions are much hotter than average, in which case post-perovskite would not be stable. The distribution of post-perovskite mapped from probabilistic tomography (Mosca et al. 2012) clearly shows that post-perovskite is present only outside LLSVPs. Post-perovskite slightly modifies seismic sensitivities to temperature and other compositional parameters (Deschamps et al. 2012), which in turn influences the interpretation of seismic tomography. The most notable effect is to slightly reduce the sensitivity of $V_{\mathrm{S}}$ to temperature and to MORB.

Based on its seismic properties, it has been proposed that lateral variations in the stability field of post-perovskite triggered by variations in temperature may explain the anti-correlation between $V_{S}$ and $V_{\Phi}$ anomalies (Hirose 2007; Hutko et al. 2008; Davies et al. 2012). Figure 15.8 displays pdf of the sensitivities of seismic velocities to the volume fraction of post-perovskite calculated following the method underlined in Sect. 15.4.2 (for details, see Deschamps et al. 2012). The mean sensitivity of $V_{\mathrm{S}}$ to post-perovskite is positive throughout the lowermost mantle (white dotted line in Fig. 15.8a), whereas the mean sensitivity of $V_{\Phi}$ is slightly negative (white dotted line in Fig. 15.8b), thus inducing anti-correlation between $V_{S}$ and $V_{\Phi}$. However, the pdf for the sensitivity of $V_{\Phi}$ spread around the zero value (Fig. 15.8b) and within the error bars it is not clear whether a transition to post-perovskite may trigger or not an anti-correlation between $V_{\mathrm{S}}$ and $V_{\Phi}$. Furthermore, it should be remembered that post-perovskite is not stable if temperature is too high and would therefore be found preferentially in regions that are colder than average. This may compensate, at least partially, the fact that bulksound velocity is slightly lower in post-perovskite than in perovskite, and lead to positive anomalies in both shear-wave and bulk-sound velocities.

The stability field of post-perovskite further implies that the phase change to post-perovskite would result in an anti-correlation between $V_{\mathrm{S}}$ and $V_{\Phi}$ anomalies in a layer of limited thickness only, typically less than $300 \mathrm{~km}$. For instance, Davies et al. (2012) do not observe any anti-correlation between their reconstructed $\mathrm{d} \ln V_{\mathrm{S}}$ and $\mathrm{d} \ln V_{\Phi}$ at $2500 \mathrm{~km}$. In tomographic models, by contrast, such anti-correlation is already present at a depth of $2500 \mathrm{~km}$ (Masters et al. 2000). The calculations of Davies et al. (2012) further predict sharp variations in the horizontally averaged $\mathrm{d} \ln V_{\mathrm{S}} / \mathrm{d} \ln V_{\mathrm{P}}$ (with values varying between -2.0 and 5.0 within a few tens of kilometers) and a strongly bimodal distribution in the values of $\mathrm{d} \ln V_{\mathrm{S}} / \mathrm{d} \ln V_{\mathrm{P}}$ at a given depth. Finally, the seismic velocity anomalies reconstructed from the temperature distribution predict large amplitude (up to $6 \%$ for $\operatorname{d} \ln V_{\mathrm{S}}$ 

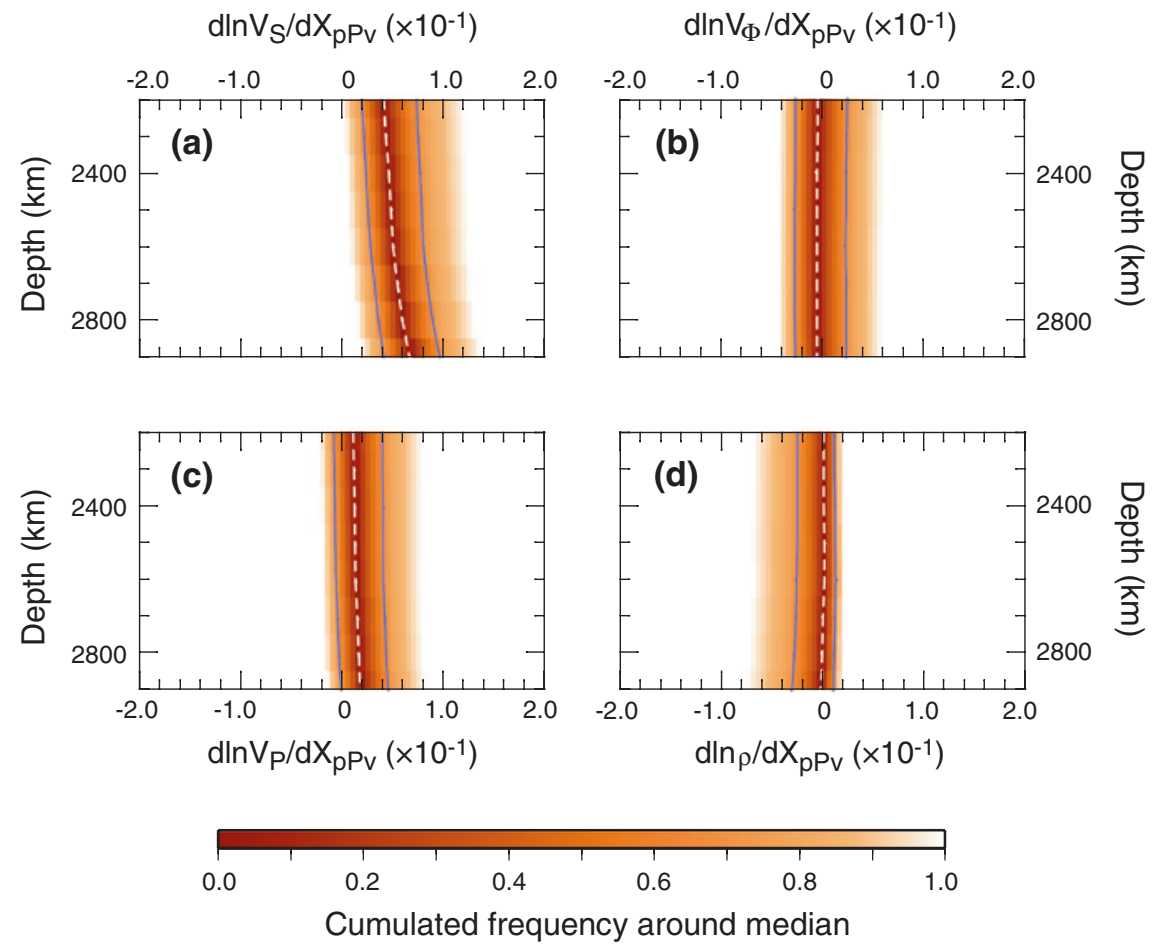

Fig. 15.8 Sensitivities of a shear-wave velocity, b bulk-sound velocity, $\mathbf{c}$ compressional-wave velocity, $\mathbf{d}$ and density to the volume fraction of post-perovskite in the depth range 2200$2900 \mathrm{~km}$. The color code indicates the cumulated likelihood around the median value. On each plot, the white dashed line indicates the median value (i.e., $50 \%$ of the explored sensitivities lie on each side of this line), and the blue curves represent the 0.15 and 0.85 quartiles (i.e., $70 \%$ of the explored sensitivities lie within the area bounded by these curves)

and more than $2 \%$ for $\operatorname{dn} V_{\Phi}$ ) and small-scale structures. None of these effects are observed by seismic tomography, although lateral and radial smearing may, at least partially, alter them.

Overall, lateral variations in the stability field of post-perovskite are unlikely to fully explain the available seismic observations, in particular the anti-correlation between $V_{\mathrm{S}}$ and $V_{\Phi}$ anomalies. Compositional anomalies are still needed to fully explain seismic tomography. Based on refined maps of probabilistic tomography, Mosca et al. (2012) reached a similar conclusion and pointed out that post-perovskite may be found outside LLSVPs only. The post-perovskite transition is, however, a good candidate to explain the D" discontinuity, at least in regions where the polarity of $\mathrm{P}$ waveforms is negative and that of $\mathrm{S}$ waveform is positive (Cobden and Thomas 2013). Furthermore, because it is strongly anisotropic (Wookey et al. 2005) and because it may inherit its fabrics from those of perovskite (Dobson et al. 2013), post-perovskite is a good candidate to explain anisotropy observed in the $\mathrm{D}^{\prime \prime}$ layer. 
Finally, even if it does not fully explain the shear-wave velocity contrast between the LLSVPs and the surrounding mantle, the presence post-perovskite outside LLSVPs certainly enhances this contrast.

\subsection{A Thermo-Chemical Lowermost Mantle}

Combined with mineral physics data, seismological observations reveal a lower mantle large-scale structure more complex than previously expected, involving phase transition ( $\mathrm{D}^{\prime \prime}$ layer), and thermo-chemical anomalies (LLSVPs). Figure 15.9 draws a simplified picture of the possible large-scale structure of the lower mantle.

Observed $\mathrm{D}^{\prime \prime}$ reflections are likely due to the transition to post-perovskite in regions where $\mathrm{P}$ and $\mathrm{S}$ waveforms have different polarities, but other explanations (including chemical changes and anisotropy) are possible in regions where both $\mathrm{P}$ and S waveforms have a positive polarity (Cobden and Thomas 2013). According to these criteria, the nature of the $\mathrm{D}^{\prime \prime}$ layer may not be unique. It may be related to the presence of post-perovskite in some regions, and to chemical and/or anisotropic effects in others. In that case, the presence of $\mathrm{D}^{\prime \prime}$ reflections within the area covered by LLSVPs does not necessarily mean that post-perovskite is stable within these regions.

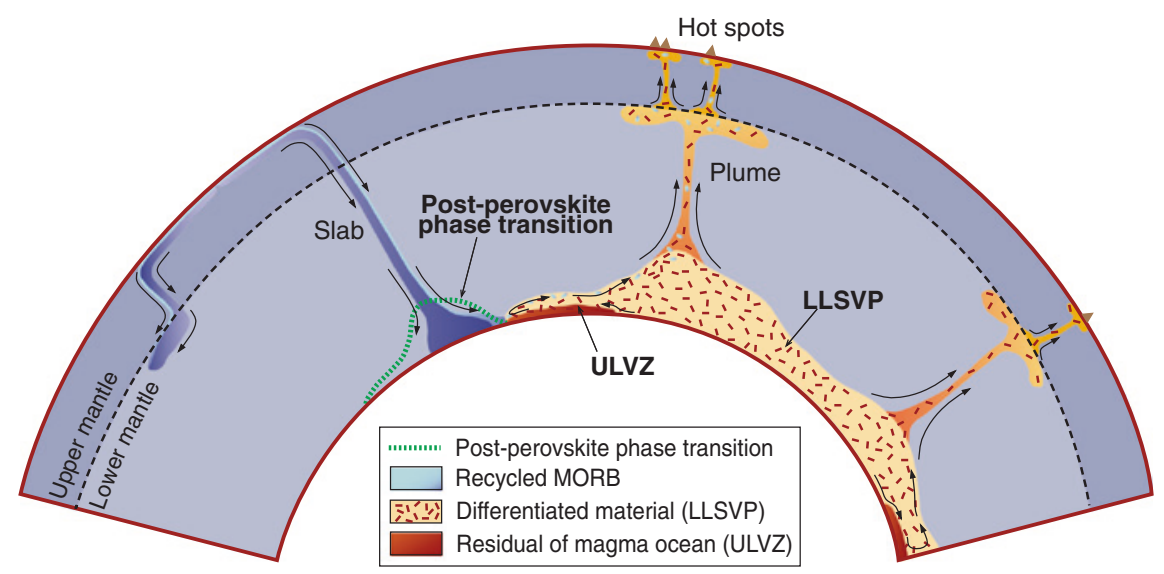

Fig. 15.9 The Earth's lower mantle? This simplified sketch shows the large-scale structures that may be present at the bottom of the Earth's mantle today. Lenses of post-perovskite are stable around slabs, with thickness that depends on the temperature. Early differentiation and possible regular re-feeding by subducted oceanic crust lead to chemically distinct structures, corresponding to the large low-shear-wave velocity provinces (LLSVPs). These structures are enriched in iron, and possibly silicates. Plumes are generated at their top and (but not uniquely) close to their edges, entraining small fraction of undegassed material and recycled oceanic crust toward the surface. Residuals of the magma ocean, strongly enriched in iron and corresponding to the ultralow velocity zones (ULVZ), are swept out toward the edge of LLSVPs 
LLSVPs clearly appear in tomographic models and cannot be explained by thermal anomalies alone. Compositional anomalies are needed to fully explain them. The exact nature of LLSVPs is still unclear, but an enrichment in iron is likely because FeO-rich minerals are seismically slower. LLSVPs are better explained by warm material enriched in iron oxide (the excess in $\mathrm{FeO}$ being distributed between ferro-periclase and Fe-perovskite) and in silicate (in the form of an excess in perovskite) than by recycled MORB, unless these MORBs are very hot (Deschamps et al. 2012). Enrichment in iron is further supported by mineral physics experiments showing that differentiation of mantle material lead to the formation of iron-rich reservoirs (Nomura et al. 2011). LLSVPs may thus result from partial differentiation in the Earth history, possible mechanisms of differentiation including the crystallization of a magma ocean (Solomatov and Stevenson 1993; Labrosse et al. 2007; Solomatov 2007), upside-down differentiation (Lee et al. 2010), and overturn of the early crust (Tolstikhin et al. 2006). Alternatively, an enrichment in iron is also consistent with E-chondrite models of Earth mantle (Kaminski and Javoy 2013; Kaminski and Javoy, this volume).

Available tomographic images show that the subducted slab may experience different fates (Kárason and van der Hilst 2000; Fukao et al. 2001). Some slabs are deflected and stacked around 700-1000 km depth (e.g., the Izu-Bonin slab), whereas others penetrate deeper into the lower mantle, possibly through avalanches (e.g., the Tonga and Central American slabs). Slabs entering the lower mantle may reach the $\mathrm{CMB}$ and stack there, in which case they would have different seismic signatures depending on their temperature (Fig. 15.7). Based on these signatures, we expect that the largest part of the subducted slab resides outside LLSVPs. However, small amounts of oceanic crust may be incorporated in LLSVPs, as recently suggested by Tackley (2012). Following this model, processes of partial differentiation of the mantle at work throughout the Earth history lead to reservoirs of distinct material, or heterogeneous basal mélange (BAM). Reservoirs of BAM may have been first created early in the Earth history and regularly re-fed since then by incorporation of small fractions of the subducted oceanic crust. This scenario is supported by recent models of convection in 2D Cartesian geometry ( $\mathrm{Li}$ et al. 2014b).

Several hints suggest that LLSVPs are stable structures and that they remained at their present location at least during the past 320 Myr. First, a major mass redistribution at the bottom of the mantle, leading to the formations of LLSVPs, would be expected to induce changes in the true polar wandering larger than those observed during the past 200 Myr (Dziewonski et al. 2010). Second, the reconstructions of the geographic positions of most LIPs during the past $320 \mathrm{Myr}$ are located above LLSVPs, mostly along their edges (Burke and Torsvik 2004; Torsvik et al. 2008). Therefore, if LLSVPs are the source regions of the LIP plumes, they must have remained at their present location since at least the past 320 Myr. Finally, mantle flow patterns inferred from tectonic plate motions reconstruction indicate that upwellings are present beneath Africa and the Pacific (i.e., above the LLSVPs) and have been stable around these locations during at least the past 250 Myr (Conrad et al. 2013). Models of thermo-chemical convection with an 
initial layer of dense material, including those discussed in this chapter (Figs. 15.5 and 15.6), show that reservoirs of dense material can remain stable for a period of time comparable to the age of the Earth without mixing substantially with the surrounding mantle. The plumes generated at the top of the reservoirs entrain small amounts of dense material, but the erosion rate is small enough to prevent mixing during the past 4.5 Gyr.

Assuming that they formed early in the Earth history, the reservoirs of dense material should be mostly undegassed. Following the BAM hypothesis (Tackley 2012) and 2D Cartesian numerical models (Li et al. 2014b), regular re-feeding by oceanic crust introduces some small patches of degassed material in these reservoirs. Thermal plumes are generated at the top of the primordial reservoirs and are entraining small amounts of dense material and, if present, recycled oceanic crust toward the surface, thus providing a probe to the chemistry of the deep reservoirs. This is consistent with OIB geochemical signatures, which indicates that OIB plumes sample both undegassed and recycled materials (e.g., Hofmann 1997). Mass balance calculations further show that the fraction of undegassed material entrained by OIB plumes is limited, $10 \%$ or less (Allègre and Moreira 2004), a value that is well explained by plume entrainment derived from models of convection (Deschamps et al. 2011).

The slow fractional crystallization of a basal magma ocean (Labrosse et al. 2007), from which LLSVPs may result, indicates that some pockets of partial melt strongly enriched in iron may exist today at the bottom of the mantle. Good candidates for such pockets are the ultra-low velocity zones (ULVZ). ULVZ, first observed by Garnero and Helmberger (1995), are thin (between 5 and $40 \mathrm{~km}$ thick) structures lying above the $\mathrm{CMB}$, in which compressional-wave $\left(V_{\mathrm{P}}\right)$ and shear-wave $\left(V_{\mathrm{S}}\right)$ velocities drop by about $10 \%$. They are usually interpreted as regions with a strong increase in density (due to chemical differentiation, e.g., an enrichment in iron) and/or partial melting (Williams and Garnero 1996; Rost et al. 2005). McNamara et al. (2010) noted that they are found predominantly in or at the edge of LLSVPs and conducted high-resolution experiments of thermo-chemical convection with three chemical components (for regular material and two types of dense material) indicating that the densest material (modeling the ULVZ) is swept out toward the edges of the reservoirs formed by the intermediate material (modeling the LLSVPs) and concentrates there.

\subsection{Conclusion and Perspectives}

Results obtained in seismology, mineral physics, and geodynamics during the past decade indicate that the large-scale structure of the lowermost mantle, between $2400 \mathrm{~km}$ depth and the CMB, likely results from several effects. Thermal variations, compositional anomalies of different sources (early mantle partial differentiation and regular recycling of oceanic crust), and the post-perovskite phase transition may all play a role and combine together to induce the observed 
seismological features, including the $\mathrm{D}^{\prime \prime}$ discontinuity and the lower mantle tomography.

Refined models of lower mantle structure, composition, and dynamics require additional observables and modeling. The electrical conductivity of mantle rocks, like their thermo-elastic properties, is sensitive to temperature and composition. Interestingly, experimental data indicate that the electrical conductivity of Earth's lower mantle minerals increases with temperature (e.g., Xu et al. 2000; Vacher and Verhoeven 2007), whereas seismic velocities and density all decrease with increasing temperature. This should help breaking the trade-offs existing between temperature and composition. Mantle electrical conductivity tomography may be obtained from time variations of the magnetic field, but to date, available data do not allow sampling the mantle at depths greater than $1600 \mathrm{~km}$ (e.g., Semenov and Kuvshinov 2012). Lateral variations in the CMB heat flux influence the magnetic field pattern at the CMB, for which observations exist. They may thus be used as an additional constrain on the lowermost mantle thermo-chemical structure. Preliminary calculations indicate that if LLSVPs are hotter than average and enriched in iron, a belt of high electrical conductivity should be present in the lowermost mantle (Deschamps, 2015). Current estimates of heat flux lateral variations used in models of geodynamo are based on temperature distributions derived from shear-wave velocity tomography (e.g., Aubert et al. 2007; Amit et al. 2010), thus neglecting the effects of chemical anomalies. Different models of dynamics and thermo-chemical structure further result in different dynamic topographies at the $\mathrm{CMB}$, which may be used as an additional constraint. Inferring the CMB topography from seismic data is, however, a difficult task, and so far no robust map of CMB topography is available. Finally, models of thermo-chemical convection that include two sources of chemical heterogeneities, i.e., recycled oceanic crust and primordial undegassed material may provide a better explanation of OIB geochemistry ( $\mathrm{Li}$ et al. 2014b) and seismic tomography.

Acknowledgments We are grateful to Dan Bower and two other anonymous colleagues for their detailed and constructive reviews that helped improving the first version of this chapter. This work was funded by Academia Sinica (Taiwan) grant AS-102-CDA-M02, National Science Council of Taiwan (NSC) grant 101-2116-M-001-001-MY3, and Swiss National Science Fundation (SNF) grants 200021_129510 and 200021_149625. Models of thermo-chemical convection shown here were calculated on the ETH Linux cluster brutus.

\section{References}

Albers M, Christensen UR (1996) The excess temperature of plumes rising from the core-mantle boundary. Geophys Res Lett 23:3567-3570

Allègre CJ, Moreira M (2004) Rare gas systematic and the origin of oceanic islands: the key role of entrainment at the $670 \mathrm{~km}$ boundary layer. Earth Planet Sci Lett 228:85-92

Allègre CJ, Hofmann AO, Nions K (1996) The Argon constraints on mantle structure. Geophys Res Lett 23:3555-3557

Amit H, Aubert J, Hulot G (2010) Stationary, oscillating or drifting mantle-driven geomagnetic flux patches? J Geophys Res 115. doi:10.1029/2009JB006542 
Anderson OL (1995) Equations of state of solids for geophysics and ceramic sciences. Oxford University Press, Oxford $405 \mathrm{pp}$

Andrault D, Muñoz M, Bolfan-Casanova N, Guignot N, Perrillat J-P, Anquilanti G, Pascarelli S (2009) Experimental evidence for perovskite and post-perovskite coexistence throughout the whole D" region. Earth Planet Sci Lett 293:90-96

Antolik M, Gu YJ, Ekström G, Dziewonski AM (2003) J362D28: a new joint model of compressional and shear velocity in the Earth's mantle. Geophys J Int 153:443-466

Anzellini S, Dewaele A, Mezouar M, Loubeyre P, Morard G (2013) Melting of iron at Earth's inner core boundary based on fast X-ray diffraction. Science 340:464-466

Aubert J, Amit H, Hulot G (2007) Detecting thermal boundary control in surface flows from numerical dynamos. Phys Earth Planet Inter 160:143-156

Austermann J, Kaye BT, Mitrovica JX, Huybers P (2014) A statistical analysis of the correlation between large igneous provinces and lower mantle seismic structure. Geophys J Int 197:1-9

Bower DJ, Gurnis M, Seton M (2013) Lower mantle structure from paleogeographically constrained dynamic Earth models. Geochem Geophys Geosys 14. doi:10.1029/2012GC004267

Boyet M, Carlson RW (2006) ${ }^{142} \mathrm{Nd}$ evidence for early ( $>4.53 \mathrm{Ga}$ ) global differentiation of the silicate Earth. Science 309:576-581

Bunge H-P (2005) Low plume excess temperature and high core heat flux inferred from nonadiabatic geotherms in internally heated mantle circulation models. Phys Earth Planet Inter 153:3-10

Burke K, Torsvik TH (2004) Derivation of large Igneous Provinces of the past 200 million years from long-term heterogeneities in the deep mantle. Earth Planet Sci Lett 227:531-538

Burke K, Steinberger B, Torsvik TH, Smethurst MA (2008) Plume generation zones at the margins of large low shear velocity provinces on the core-mantle boundary. Earth Planet Sci Lett 265:49-60

Campbell IH, Griffiths RW (1990) Implications of mantle plume structure for the evolution of flood basalts. Earth Planet Sci Lett 99:79-93

Caracas R, Cohen RE (2005) Effects of chemistry on the stability and elasticity of the perovskite and post-perovskite phases in the $\mathrm{MgSiO}_{3}-\mathrm{FeSiO}_{3}-\mathrm{Al}_{2} \mathrm{O}_{3}$ system and implications for the lowermost mantle. Geophys Res Lett 32. doi:10.1029/2005GL023164

Caracas R, Cohen RE (2007) Effect of chemistry on the physical properties of perovskite and post-perovskite. In: Hirose $\mathrm{K}$ et al (eds) Post-perovskite the last mantle phase transition, vol 174. Geophysical Monograph. American Geophysical Union, pp 115-128

Caro G, Bourdon B, Birck JL, Moorbath S $(2003){ }^{146} \mathrm{Sm}^{-142} \mathrm{Nd}$ evidence from Isua metamorphosed sediments for early differentiation of the Earth's mantle. Nature 423:428-432

Caro G, Bourdon B, Wood BJ, Corgne A (2004) Trace-element fractionation in Hadean mantle generated by melt segregation from a magma ocean. Nature 436:246-249

Christensen UR (1989) Models of mantle convection: one or several layers. Phil Trans R Soc London A 328:417-424

Christensen UR, Hofmann AW (1994) Segregation of subducted oceanic crust in the convecting mantle. J Geophys Res 99:19867-19884

Christensen UR, Yuen DA (1985) Layered convection induced by phase transitions. J Geophys Res 90:10291-10300

Cobden L, Thomas C (2013) The origin of $\mathrm{D}^{\prime \prime}$ reflections a systematic study of seismic array data sets. Geophys J Int 194:1091-1118

Cobden L, Mosca I, Trampert J, Ritsema J (2012) On the likelihood of post-perovskite near the core-mantle boundary: a statistical interpretation of seismic observations. Phys Earth Planet Inter 210-211:21-35

Connolly JAD (2005) Computation of phase equilibria by linear programming: a tool for geodynamic modeling and its application to subduction zone decarbonisation. Earth Planet Sci Lett 236:524-541

Conrad CP, Steinberger B, Torsvik TH (2013) Stability of active mantle upwelling revealed by net characteristics of plate tectonics. Nature 498:479-482 
Davaille A (1999) Simultaneous generation of hotspots and superswells by convection in a heterogeneous planetary mantle. Nature 402:756-760

Davies DR, Goes S, Davies JH, Schuberth BSA, Bunge H-P, Ritsema J (2012) Reconciling dynamic and seismic models of Earth's lower mantle: the dominant role of thermal heterogeneity. Earth Planet Sci Lett 353-354:253-269

Deschamps, (2015) Lower mantle electrical conductivity inferred from probabilistic tomography. Terr Atmos Ocean Sci 26:27-40. doi:10.3319/TAO.2014.08.19.03(GRT)

Deschamps F, Tackley PJ (2008) Exploring the model space of thermo-chemical convection I-principles and influence of the rheological parameters. Phys Earth Planet Inter 171:357-373

Deschamps F, Tackley PJ (2009) Searching for models of thermo-chemical convection that explain probabilistic tomography. II. Influence of physical and compositional parameters. Phys Earth Planet Inter 176:1-18

Deschamps F, Trampert J (2003) Mantle tomography and its relation to temperature and composition. Phys Earth Planet Inter 140:277-291

Deschamps F, Trampert J, Tackley PJ (2007) Thermo-chemical structure of the lower mantle: seismological evidence and consequences for geodynamics. In Yuen DA et al (eds) Superplume: beyond plate tectonics. Springer, Berlin, pp 293-320

Deschamps F, Kaminski E, Tackley PJ (2011) A deep mantle origin for the primitive signature of Ocean Island Basalt. Nat Geosci 4:879-882

Deschamps F, Cobden L, Tackley PJ (2012) The primitive nature of large low shear-wave velocity provinces. Earth Planet Sci Lett 349-350:198-208

Dobson DP, Miyajima N, Nestola F, Alvaro M, Casati N, Liebske C, Wood IG, Walker AM (2013) Strong inheritance of texture between perovskite and post-perovskite in the $\mathrm{D}^{\prime \prime}$ layer. Nat Geosci 6:575-578

Dziewonski AM, Lekic V, Romanowicz B (2010) Mantle anchor structure: an argument for bottom up tectonics. Earth Planet Sci Lett 299:69-79

Farley KA, Natland JH, Craig H (1992) Binary mixing of enriched and undegassed (primitive?) mantle components (He, $\mathrm{Sr}, \mathrm{Nd}, \mathrm{Pb})$ in Samoan lavas. Earth Planet Sci Lett 111:183-199

Farnetani CG (1997) Excess temperature of mantle plumes: the role of chemical stratification across D". Geophys Res Lett 24:1583-1586

Fukao Y, Widiyantoro S, Obayashi M (2001) Stagnant slabs in the upper and lower transition regions. Rev Geophys 39:291-323

Garnero EJ, Helmberger DV (1995) A very slow basal layer underlying large-scale low-velocity anomalies in the lower mantle beneath the Pacific: evidence from core phases. Earth Planet Sci Lett 91:161-176

Gurnis M (1986) The effect of chemical density differences on convective mixing in the Earth's mantle. J Geophys Res 91:11407-11419

Hansen U, Yuen DA (1988) Numerical simulations of thermo-chemical instabilities at the coremantle boundary. Nature 334:237-240

He Y, Wen L (2009) Structural features and shear-velocity structure of the "Pacific Anomaly". J Geophys Res 114. doi:10.1029/2008JB005814

Hernlund J, Houser C (2008) On the statistical distribution of seismic velocities in Earth's deep mantle. Earth Planet Sci Lett 265:423-437

Hernlund J, Thomas C, Tackley PJ (2005) A doubling of the post-perovskite phase boundary and structure of the Earth's lowermost mantle. Nature 434:882-886

Hirose K (2002) Phase transitions in pyrolitic mantle around 670-km depth: implications for upwelling of plumes from the lower mantle. J Geophys Res 107. doi:10.1029/200 1JB000597

Hirose K (2007) Discovery of post-perovskite phase transition and the nature of the $\mathrm{D}^{\prime \prime}$ layer. In: Hirose K et al (eds) Post-perovskite the last mantle phase transition, vol 174. Geophysical Monograph. American Geophysical Union, pp 19-35

Hofmann AW (1997) Mantle geochemistry: the message from oceanic volcanism. Nature 385:219-229 
Houser C, Masters G, Shearer P, Laske G (2008) Shear and compressional velocity models of the mantle from cluster analysis of long-period waveforms. Geophys J Int 174:195-212

Humayun M, Qin L, Norman ND (2004) Geochemical evidence for excess iron in the Mantle beneath Hawaii. Science 306:91-94

Hutko AR, Lay T, Revenaugh J, Garnero EJ (2008) Anticorrelated seismic velocity anomalies from post-perovskite in the lowermost mantle. Science 320:1070-1074

Ishii M, Tromp J (1999) Normal-mode and free-air gravity constraints on lateral variations in velocity and density of Earth's mantle. Science 285:1231-1236

Jackson MG, Carlson RW, Kurz MD, Kempton PD, Francis D, Blusztajn J (2010) Evidence for the survival of the oldest terrestrial mantle reservoir. Nature 466:853-856

Jaupart C, Molnar P, Cottrell E (2007) Instability of a chemically dense layer heated from below and overlain by a deep less viscous fluid. J Fluid Mech 572:433-469

Javoy M, Kaminski E, Guyot F, Andrault D, Sanloup C, Moreira M, Labrosse S, Jambon A, Agrinier P, Davaille A, Jaupart C (2010) The chemical composition of the Earth: enstatite chondrite model. Earth Planet Sci Lett 293:259-268

Jellinek AM, Manga M (2002) The influence of a chemical boundary layer on the fixity, spacing and lifetime of mantle plumes. Nature 418:760-763

Kageyama A, Sato T (2004) "Yin-Yang grid": an overset grid in spherical geometry. Geochem Geophys Geosyst 5. doi:10.1029/2004GC000734

Kaminski E, Javoy M (2013) A two-stage scenario for the formation of the Earth's mantle and core. Earth Planet Sci Lett 365:97-107

Kaminski E, Javoy M (2014) The composition of the deep Earth. In: Khan A et al (eds) The heterogeneous Earth mantle (in press)

Kárason H, van der Hilst RD (2000) Constraints on mantle convection from mantle tomography. In: Richards MA et al (eds) The history and dynamics of global plate motions, vol 121 . Geophysical Monograph. American Geophysical Union, pp 277-288

Kiefer B, Stixrude L, Wentzcovitch RM (2002) Elasticity of $(\mathrm{Mg}, \mathrm{Fe}) \mathrm{SiO}_{3}$ perovskite at high pressures. Geophys Res Lett 29. doi:10.1029/2002GL014683

Kung J, Li B, Weidner DJ, Zhang J, Liebermann RC (2002) Elasticity of (Mg 0.83, Fe 0.17) $\mathrm{O}$ ferropericlase at high pressure: ultrasonic measurements in conjunction with $\mathrm{X}$-radiation techniques. Earth Planet Sci Lett 203:557-566

Kustowski B, Ekström G, Dziewonski AM (2008) Anisotropic shear-wave velocity structure of the Earth's mantle: a global model. J Geophys Res 113:B06306. doi:10.1029/2007JB005169

Labrosse S, Hernlund JW, Coltice N (2007) A crystallizing dense magma ocean at the base of the Earth's mantle. Nature 450:866-869

Le Bars M, Davaille A (2004) Whole layer convection in a homogeneous planetary mantle. J Geophys Res 109. doi:10.1029/2003JB002617

Lee C-T, Luffi P, Hoink T, Li J, Dasgupta R, Hernlund J (2010) Upside-down differentiation and generation of a 'primordial' lower mantle. Nature 463:930-933

Lekic V, Cottaar S, Dziewonski AM, Romanowicz B (2012) Cluster analysis of global lower mantle tomography: a new class of structure and implications for chemical heterogeneity. Earth Planet Sci Lett 357-358:68-77

Li M, McNamara AK (2013) The difficulty for subducted oceanic crust to accumulate at the Earth's core-mantle boundary. J Geophys Res 118:1807-1816. doi:10.1002/jgrb.50156

Li X-D, Romanowicz B (1996) Global mantle shear velocity model developed using nonlinear asymptotic coupling theory. J Geophys Res 101:22245-22272

Li Y, Deschamps F, Tackley PJ (2014a) The stability and structure of primordial reservoirs in the lower mantle: insights from models of thermo-chemical convection in 3-D spherical geometry. Geophys J Int (submitted)

Li M, McNamara AK, Garnero EJ (2014b) Chemical complexity of hotspots caused by cycling oceanic crust through mantle reservoirs. Nat Geosci 7:366-370

Machetel P, Weber P (1991) Intermittent layered convection in a model mantle with an endothermic phase change at $670 \mathrm{~km}$. Nature 350:55-57 
Mao W, Shen G, Prakapenka VB, Meng Y, Campbell AJ, Heinz D, Shu J, Hemley RJ, Mao HK (2004) Ferromagnesian perovskite silicates in the D" layer of the Earth. Proc Natl Acad Sci USA 101:15867-15869

Mao W, Campbell AJ, Prakapenka VB, Hemley RJ, Mao H-K (2007) Effect of iron on the properties of post-perovskite silicate. In: Hirose K et al (eds) Post-perovskite the last mantle phase transition, vol 174. Geophysical Monograph. American Geophysical Union, pp 37-46

Masters G, Laske G, Bolton H, Dziewonski AM (2000) The relative behavior of shear velocity, bulk sound speed, and compressional velocity in the mantle: implication for thermal and chemical structure. In Karato S-I et al (eds) Earth's deep interior: mineral physics and tomography from the atomic to the global scale, vol 117. Geophysical Monograph Series. American Geophysical Union, Washington, DC, pp 63-87

McNamara AK, Zhong S (2004) Thermochemical structures within a spherical mantle. J Geophys Res 109. doi:10.1029/2003JB002847

McNamara AK, Zhong S (2005) Thermochemical structure beneath Africa and the Pacific ocean. Nature 437:1136-1139

McNamara AK, Garnero EJ, Rost S (2010) Tracking deep mantle reservoirs with ultra-low velocity zones. Earth Planet Sci Lett 299:1-9

Mittelstaedt E, Tackley PJ (2005) Plume heat flow is much less than CMB heat flow. Earth Planet Sci Lett 241:202-210

Mosca I, Cobden L, Deuss A, Ritsema J, Trampert J (2012) Seismic and mineralogical structures of the lower mantle from probabilistic tomography. J Geophys Res 117:B06304. doi:10.102 9/2011JB008851

Murakami M, Hirose K, Kawamura K, Sata N, Ohishi Y (2004) Post-perovskite phase transition in $\mathrm{MgSiO}_{3}$. Science 304:855-858

Nakagawa T, Tackley PJ (2004) Effects of thermo-chemical convection on the thermal evolution of the Earth's core. Earth Planet Sci Lett 220:207-219

Nakagawa T, Tackley PJ (2005a) The interaction between the post-perovskite phase change and a thermo-chemical boundary layer near the core-mantle boundary. Earth Planet Sci Lett 238:204-216

Nakagawa T, Tackley PJ (2005b) Deep mantle heat flow and thermal evolution of Earth's core in thermo-chemical multiphase models of mantle convection. Geochem Geophys Geosyst 6 . doi:10.1029/2005GC000967

Nakagawa T, Tackley PJ (2014) Influence of combined primordial layering and recycled MORB on the coupled thermal evolution of Earth's mantle and core. Geochem Geophys Geosyst 15:619-633. doi:10.1002/2013GC005128

Nakagawa T, Tackley PJ, Deschamps F, Connolly JAD (2010) The influence of MORB and harzburgite composition on thermo-chemical mantle convection in a 3D Spherical shell with self-consistently calculated mineral physics. Earth Planet Sci Lett 296:403-412

Ni S, Helmberger D (2003) Ridge-like lower mantle structure beneath South Africa. J Geophys Res 108. doi:10.1029/2001JB001545

Ni S, Tan E, Gurnis M, Helmberger D (2002) Sharp sides to the African superplumes. Science 296:1850-1852

Nomura R, Ozawa H, Tateno S, Hirose K, Hernlund J, Muto S, Ishii H, Hiraoka N (2011) Spin crossover and iron-rich silicate melt in the Earth's deep mantle. Nature 473:199-203

Nomura R, Hirose K, Uesugi K, Ohishi Y, Tsuchiyama A, Miyake A, Ueno Y (2014) Low coremantle boundary temperature inferred from the solidus of pyrolite. Science 343:522-525

Oganov AR, Ono S (2004) Theoretical and experimental evidence for a post-perovskite phase of $\mathrm{MgSiO}_{3}$ in Earth's D" layer. Nature 430:445-448

Ohta K, Hirose K, Lay T, Stat N, Ohishi Y (2008) Phase transitions in pyrolite and MORB at lowermost mantle conditions: implication for a MORB-rich pile above the core-mantle boundary. Earth Planet Sci Lett 267:107-117

Olson P, Kincaid C (1991) Experiment on the interaction of thermal convection and compositional layering at the base of the mantle. J Geophys Res 96:4347-4354 
Parmentier EM, Sotin C, Travis BJ (1994) Turbulent 3-D thermal convection in an infinite Prandtl number, volumetrically heated fluid-implications for mantle dynamics. Geophys J Int 116:241-251

Resovsky JS, Trampert J (2003) Using probabilistic seismic tomography to test mantle velocitydensity relationships. Earth Planet Sci Lett 215:121-134

Ricard Y, Mattern E, Matas J (2005) Synthetic tomographic images of slabs from mineral physics. In: van der Hilst RD et al (eds) Earth's deep mantle: Structure, composition and evolution, vol 160. American Geophysical Union, Geophysical Monograph, pp 285-302

Ringwood AE (1975) Composition and petrology of the Earth mantle. McGraw-Hill, New York, $618 \mathrm{pp}$

Ritsema J, van Heijst H (2000) Seismic imaging of structural heterogeneity in Earth's mantle: evidence for large-scale mantle flow. Sci Progress 83:243-259

Ritsema J, van Heijst H, Woodhouse JH (1999) Complex shear-wave velocity structure imaged beneath Africa and Iceland. Science 286:1925-1928

Ritsema J, McNamara AK, Bull AL (2007) Tomographic filtering of geodynamic models: implications for model interpretation and large-scale mantle structure. J Geophys Res 112. doi:10 .1029/2006JB004566

Ritsema J, Deuss A, vanHeijst H-J, Woodhouse JH (2011) S40RTS: a degree-40 shear-velocity model for the mantle from new Rayleigh wave dispersion, teleseismic traveltime and normal-mode splitting function measurements. Geophys J Int 184:1223-1236

Rost S, Garnero EJ, Williams Q, Manga M (2005) Seismological constraints on a possible plume root at the core-mantle boundary. Nature 435:666-669

Schott B, Yuen DA (2004) Influences of dissipation and rheology on mantle plumes coming from the D"-layer. Phys Earth Planet Inter 146:139-145

Schuberth BSA, Bunge H-P, Ritsema J (2009) Tomographic filtering of high resolution mantle circulation models: can seismic heterogeneity be explained by temperature alone? Geochem Geophys Geosyst 10. doi:10.1029/2009GC002401

Schuberth BSA, Zaroli C, Nolet G (2011) Synthetic seismograms for a synthetic Earth: longperiod $P$ - and $S$-wave traveltime variations can be explained by temperature alone. Geophys J Int 188:1393-1412

Semenov A, Kuvshinov A (2012) Global 3-D imaging of mantle conductivity based on inversion of observatory $C$-responses-II. Data analysis and results. Geophys J Int 191:965-992

Sinmyo R, Hirose K, Muto S, Ohishi Y, Yasuhara A (2011) The valence state and partitioning of iron in the Earth's lowermost mantle. J Geophys Res 116. doi:10.1029/2010JB008179

Solomatov VS (2007) Magma oceans and primordial mantle differentiation. In: Stevenson DJ (ed) Treatise on geophysics, vol 9., Earth formation and evolutionElsevier B.V., Amsterdam, pp 91-119

Solomatov VS, Stevenson DJ (1993) Suspension in convective layers and style of differentiation of a terrestrial magma ocean. J Geophys Res 98:5375-5390

Stackhouse S, Brodholt JP (2007) The high-temperature elasticity of $\mathrm{MgSiO}_{3}$ post-perovskite silicate. In: Hirose K et al (eds) Post-perovskite the last mantle phase transition,vol 174. Geophysical Monograph. American Geophysical Union, pp 99-114

Stackhouse S, Brodholt JP, Wookey J, Kendal J-M, Price GD (2005) The effect of temperature on the seismic anisotropy of the perovskite and post-perovskite polymorphs of $\mathrm{MgSiO}_{3}$. Earth Planet Sci Lett 230:1-10

Stixrude L, Lithgow-Bertelloni C (2011) Thermodynamics of mantle minerals-II. Phase equilibria. Geophys J Int 184:1180-1213

Stuart FM, Lass-Evans S, Fitton JG, Ellam RM (2003) High ${ }^{3} \mathrm{He} /{ }^{4} \mathrm{He}$ ratios in picritic basalts from Baffin Island and the role of a mixed reservoir in mantle plumes. Nature 424:57-59

Su W-J, Dziewonski AM (1997) Simultaneous inversion for 3-D variations in shear and bulk velocity in the mantle. Phys Earth Planet Inter 100:135-156

Su W-J, Woodward RL, Dziewonski AM (1994) Degree 12 model of shear velocity heterogeneity in the mantle. J Geophys Res 99:6945-6980 
Tackley PJ (1998) Three-dimensional simulations of mantle convection with a thermo-chemical CMB boundary layer: $\mathrm{D}^{\prime \prime}$ ? In: Gurnis $\mathrm{M}$ et al (eds) The core-mantle boundary region, vol 28. Geodynamical series, pp 231-253

Tackley PJ (2002) Strong heterogeneity caused by deep mantle layering. Geochem Geophys Geosyst 3. doi:10.1029/2001GC000167

Tackley PJ (2008) Modelling compressible mantle convection with large viscosity contrasts in a three-dimensional spherical shell using the yin-yang grid. Phys Earth Planet Inter 171:7-18

Tackley PJ (2012) Dynamics and evolution of the deep mantle resulting from thermal, chemical, phase and melting effects. Earth Sci Rev 110:1-25

Tackley PJ, King SD (2003) Testing the tracer ratio method for modelling active compositional fields in mantle convection simulations. Geochem Geophys Geosyst 4:Q08302

Tackley PJ, Stevenson DJ, Glatzmaier GA, Schubert G (1993) Effects of an endothermic phase transition at $670 \mathrm{~km}$ depth in a spherical model of convection in the Earth's mantle. Nature 361:699-704

Tackley PJ, Stevenson DJ, Glatzmaier GA, Schubert G (1994) Effects of multiple phase transition in a 3-D spherical model of convection in Earth's mantle. J Geophys Res 99:15877-15901

Takeushi N, Morita Y, Xuyen ND, Zung NQ (2008) Extent of the low-velocity region in the lowermost mantle beneath the western Pacific detected by the Vietnamese Broadband Seismograph Array. Geophys Res Lett 35. doi:10.1029/2008GL033197

Tan E, Gurnis M (2005) Metastable superplumes and mantle compressibility. Geophys Res Lett 32. doi:10.1029/2005GL024190

Tan E, Gurnis M (2007) Compressible thermo-chemical convection and application to the lower mantle. J Geophys Res 112. doi:10.1029/2006JB004505

Tan E, Gurnis M, Han L (2002) Slabs in the lower mantle and their modulation of plume formation. Geochem Geophys Geosyst 3. doi:10.1029/2001GC000238

Tan E, Leng W, Zhong S, Gurnis M (2011) On the location of plumes and lateral movement of thermochemical structures with high bulk modulus in the 3-D compressible mantle. Geochem Geophys Geosyst 7. doi:10.1029/2011GC003665

Tanimoto T (1990) Long-wavelength S-wave velocity structure throughout the mantle. Geophys J Int 100:327-336

Tateno S, Hirose K, Sata N, Ohishi Y (2009) Determination of post-perovskite phase transition boundary up to $4400 \mathrm{~K}$ and implications for thermal structure in D" layer. Earth Planet Sci Lett 277:130-136. doi:10.1016/j.eps1.2008.10.004

To A, Romanowicz B, Capdeville Y, Takeuchi N (2005) 3D effects of sharp boundaries at the border of the African and Pacific superplumes: observations and modeling. Earth Planet Sci Lett 233:137-153

Tolstikhin IN, Kramers JD, Hofmann AW (2006) A chemical Earth model with whole mantle convection: the importance of a core-mantle boundary layer $\left(\mathrm{D}^{\prime \prime}\right)$ and its early formation. Chem Geol 226:79-99

Torsvik TH, Steinberger B, Cocks LRM, Burke K (2008) Longitude: linking Earth's ancient surface to its deep interior. Earth Planet Sci Lett 276:273-282

Trampert J, Vacher P, Vlaar N (2001) Sensitivities of seismic velocities to temperature, pressure and composition in the lower mantle. Phys Earth Planet Inter 124:255-267

Trampert J, Deschamps F, Resovsky JS, Yuen DA (2004) Probabilistic tomography maps significant chemical heterogeneities in the lower mantle. Science 306:853-856

Tsuchiya T, Tsuchiya J, Umemoto K, Wentzcovitch RM (2004a) Phase transition in $\mathrm{MgSiO}_{3}$ perovskite in the Earth's lower mantle. Earth Planet Sci Lett 224:241-248

Tsuchiya T, Tsuchiya J, Umemoto K, Wentzcovitch RM (2004b) Elasticity of post-perovskite $\mathrm{MgSiO}_{3}$. Geophys Res Lett 31. doi:10.1029/2004GL020278

Vacher P, Verhoeven O (2007) Modelling the electrical conductivity of iron-rich minerals for planetary applications. Planet Space Sci 55:455-456

van der Hilst RD, Kárason H (1999) Compositional heterogeneity in the bottom 1000 kilometers of Earth's mantle: towards a hybrid convection model. Science 283:1885-1888 
van der Hilst RD, Widiyantoro S, Engdahl ER (1997) Evidence for deep mantle circulation from seismic tomography. Nature 386:578-584

van Thienen P, van den Berg AP, Vlaar NJ (2004) Production and recycling of oceanic crust in the early Earth. Tectonophysics 386:41-65

van Thienen P, van Summeren J, van der Hilst RD, van den Berg AP, Vlaar NJ (2005) Numerical study of the origin and stability of chemically distinct reservoirs deep in Earth's mantle. In: van der Hilst RD et al (eds) Earth's deep mantle: structure, evolution and composition, vol 160. American Geophysical Union, Geophysical Monograph, pp 117-136

Wang Y, Wen L (2007) Geometry and P and S velocity structure of the "African anomaly". J Geophys Res 112. doi:10.1029/2006JB004483

Williams Q, Garnero EJ (1996) Seismic evidence for partial melt at the base of the Earth mantle. Science 273:1528-1530

Wookey J, Stackhouse S, Kendall JM, Brodholt J, Price GD (2005) Efficacy of the postperovskite phase as an explanation for lowermost-mantle seismic properties. Nature 438:1004-1007

Wysession ME, Lay T, Revenaugh J, Williams Q, Garnero EJ, Jeanloz R, Kellogg LH (1998) The $\mathrm{D}^{\prime \prime}$ discontinuity and its implications. In: Gurnis $\mathrm{M}$ et al (eds) The core-mantle boundary region, vol 28. Geodynamical series, pp 231-253

Xu Y, Shankland TJ, Brent TP (2000) Laboratory based electrical conductivity in the Earth's mantle. J Geophys Res 105:27865-27875

Zhang N, Zhong S, Leng W, Li Z-X (2010) A model for the evolution of the Earth's mantle structure since the early paleozoic. J Geophys Res 115. doi:10.1029/2009JB006896 